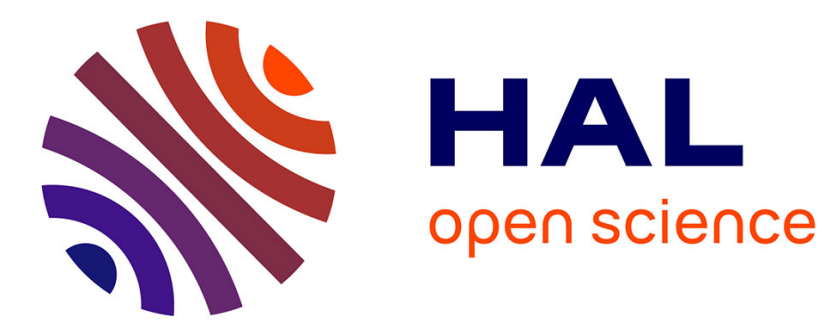

\title{
Production et diffusion au Chalcolithique des lames en silex du Ludien de Collorgues (Gard)
}

\author{
Maxime Remicourt, Jean Vaquer, Marc Bordreuil
}

\section{To cite this version:}

Maxime Remicourt, Jean Vaquer, Marc Bordreuil. Production et diffusion au Chalcolithique des lames en silex du Ludien de Collorgues (Gard). Gallia Préhistoire - Préhistoire de la France dans son contexte européen, 2009, 51, pp.213-244. 10.3406/galip.2009.2479 . hal-02050665v2

\section{HAL Id: hal-02050665 \\ https://hal-univ-tlse2.archives-ouvertes.fr/hal-02050665v2}

Submitted on 2 Jan 2020

HAL is a multi-disciplinary open access archive for the deposit and dissemination of scientific research documents, whether they are published or not. The documents may come from teaching and research institutions in France or abroad, or from public or private research centers.
L'archive ouverte pluridisciplinaire HAL, est destinée au dépôt et à la diffusion de documents scientifiques de niveau recherche, publiés ou non, émanant des établissements d'enseignement et de recherche français ou étrangers, des laboratoires publics ou privés.

\section{(1) (1) $\$$}

Distributed under a Creative Commons Attribution - NonCommercial - NoDerivatives 44.0 


\title{
PRODUCTION ET DIFFUSION
}

AU CHALCOLITHIQUE DES LAMES

EN SILEX DU LUDIEN DE COLLORGUES (GARD)

\author{
Maxime REMICOURT*, Jean VAQUER** et Marc BORDREUIL***
}

\begin{abstract}
Mots-clés. Collorgues, Chalcolithique, lames en silex, mines, production, échanges.
Résumé. Cet article propose un bilan des connaissances sur l'exploitation du silex du Ludien du bassin tertiaire de Collorgues (Gard) à la fin du Néolithique et au Chalcolithique. Au XIX siècle, les premières recherches ont interprété les structures de Collorgues comme des hypogées, mais les études menées par la suite ont indiqué qu'elles étaient à l'origine des galeries d'extraction de silex pour la production de pièces bifaciales à partir de silex en plaquettes et de lames à partir de silex en plaques. Récemment, l'étude des séries archéologiques issues des fouilles et des ramassages de surface des environs de Collorgues a révélé la présence de plusieurs ateliers spécialisés de production laminaire à proximité des gîtes de matière première. Ces données, conjuguées à celles acquises sur les pièces laminaires exportées dans une partie du midi de la France, ont mis en relief le tri et le choix des lames de plein débitage pour les échanges. Ces enquêtes ont également permis de délimiter une aire de diffusion préférentielle concernée par ces exportations et de proposer un cadre chronologique que l'on peut placer grosso modo entre 3300 et 2400 av. J.-C. pour la mise en place et la fin de ce phénomène.
\end{abstract}

Keys-words. Collorgues, Chalcolithic, flint blades, mines, production, exchanges.

Abstract. This article presents a synthesis of our knowledge of the exploitation of Ludian flint from the tertiary basin of Collorgues (Gard department) at the end of the Neolithic and during the Chalcolithic period. During the 19th century, early research was conducted on the pseudo-hypogea of Collorgues. Later studies, however, revealed that these structures were originally flint extraction galleries for the production of bifacial pieces from small flint plaques and blades from larger plaques. A recent study of archaeological assemblages originating from excavations and surface collections in proximity to Collorgues has revealed the presence of several workshops specialised in blade production near the raw material sources. These data, integrated with those collected from the study of blades exported to part of the Midi region in southern France, have revealed a selection of full debitage phase blades for exchanges. These studies have also allowed us to delimit a preferential diffusion zone concerned by these exportations and to propose a chronological framework that we can situate roughly between 3300 and 2400 BC for the development and end of this phenomenon.

Translation: Magen O'FARRELL

Schlüsselwörter. Collorgues, Chalkolithikum, Silexklingen, Bergbau, Produktion, Handel.

Zusammenfassung. Dieser Artikel zieht eine Bilanz der Kenntnisse bezüglich der Ausbeutung des Silex des Ludien aus dem Tertiärbecken von Collorgues am Ende des Neolithikums und im Chalkolithikum. Die ersten Forscher im 19. Jahrhundert interpretierten die Strukturen als Hypogäen, doch spätere Untersuchungen haben gezeigt, dass es sich in Wirklichkeit um Galerien für den Abbau von Silex handelte, welcher der Herstellung bifazialer Geräte aus Silexplättchen und Klingen aus Silexplatten diente. Kürzlich wurden

\footnotetext{
* EHESS, UMR 5608 TRACES (CNRS, Université Toulouse-2, EHESS, Sous-direction de l'Archéologie, INRAP), CRPPM, 39, allées Jules Guesde, 31000 Toulouse. Tél.: 0468725829 - Courriel: m.remicourt@laposte.net

** UMR 5608 TRACES (CNRS, Université Toulouse-2, EHESS, Sous-direction de l'Archéologie, INRAP), CRPPM, 39, allées Jules Guesde, 31000 Toulouse. Tél.: 0468725829 - Courriel: jean-sebastien.vaquer@orange.fr

*** Conservateur honoraire des Musées d'Alès, 35, Faubourg d'Auvergne, 30100 Alès. Tél.: 0466301149 - Courriel: mc.bordreuil@wanadoo.fr
} 
die Inventare aus den Grabungen und die in der Umgebung von Collorgues gesammelten Rohstücke untersucht, dabei konnte die Präsenz mehrerer auf die Klingenproduktion spezialisierter Werkstätten in der Nähe der Rohstofflagerstätten aufgezeigt werden. Diese Daten, verbunden mit den Untersuchungsergebnissen zu den in einen Teil Südfrankreichs exportierten Klingen, haben ergeben, dass offensichtlich die regelmäßigen Klingen ausgewählt und ausgetauscht wurden. Diese Untersuchungen haben es ebenfalls ermöglicht, ein Verbreitungsgebiet für diese Exporte einzugrenzen und einen chronologischen Rahmen vorzuschlagen, den man grosso modo zwischen 3300 und 2400 v. Chr. ansetzen kann.

Übersetzung: Isa ODENHARDT-DONVEZ

À la fin du Néolithique, vers 3500 av. J.-C., le midi de la France est marqué par de nombreux changements. Dans le domaine de l'industrie lithique en particulier, on constate l'arrêt de la diffusion massive des nucléus à lamelles en silex blond bédoulien préformés et traités thermiquement qui assuraient l'essentiel des besoins durant le Chasséen récent. Ce sont désormais des lames de moyen format (entre $12 \mathrm{~cm}$ et $18 \mathrm{~cm}$ de longueur), à grand $(18 \mathrm{~cm}$ à $25 \mathrm{~cm})$, voire à très grand format $(>25 \mathrm{~cm})$ qui deviennent les outils emblématiques de la fin du Néolithique et du Chalcolithique. Ces productions laminaires, de format généralement supérieur aux lames chasséennes, sont au départ fabriquées dans les ateliers provençaux des environs du mont Ventoux (Vaucluse) et du bassin d'Apt-Forcalquier (Alpes-de-HauteProvence), qui fonctionnaient précédemment de façon restreinte (Léa, 2004; Renault, 1998 et 2006). Cette réorientation de la production s'accompagne d'une amélioration technique due à l'application de la pression renforcée au levier pour le débitage des grandes à très grandes lames. Dans la seconde moitié du IV e millénaire l'accroissement de la demande en lames brutes, voire en poignards façonnés reproduisant les premiers morphotypes en cuivre importés, est tel que de nouveaux ateliers de production de lames apparaissent et se développent dans certaines régions favorables. C'est le cas en particulier dans le bassin de Collorgues-Aubussargues dans le Gard, où des galeries d'abord interprétées comme des sépultures collectives en hypogées ont ensuite été reconnues comme d'authentiques mines de silex. Cette reconnaissance tardive n'a pas permis de cerner les objectifs de production de ces extractions massives de silex et, pendant quelques temps, on a supposé que ces mines avaient pour vocation l'extraction de silex en plaquettes ou de nodules pour produire des outillages bifaciaux ou sur éclats dans le style des industries «des pasteurs des plateaux» (Hugues et al., 1965a, 1974).
Dans le cadre de recherches sur la circulation des matières premières lithiques menées dans deux projets collectifs de recherche, l'un, coordonné par H. Plisson, sur les productions laminaires remarquables en Languedoc et en Provence, et l'autre, coordonné par J. Vaquer, sur les poignards chalcolithiques en Midi-Pyrénées, le lien a pu être établi entre le silex de Collorgues et de nombreuses lames retrouvées en Languedoc-Roussillon et en Midi-Pyrénées. Ce qui apparaissait comme une production marginale de lames mal venues sur les ateliers a dû être fortement reconsidéré et a motivé une relance des recherches sur les sites d'ateliers de taille des environs de Collorgues. C'est alors qu'un exemple très probant d'atelier de production laminaire a été reconnu sur le site du Pouget à Saint-Maurice-de-Cazevieille, dans le Gard (Briois, 2006). Au cours des dernières années, les recherches sur le terrain et dans les collections régionales se sont intensifiées, notamment dans le cadre des recherches doctorales de l'un de nous (M. R.).

Les objectifs de ces investigations sont multiples. Il s'agit en premier lieu de recenser et de contrôler les excavations pénétrables considérées comme des mines de silex pour en apprécier l'importance dans le bassin de Collorgues. Un inventaire des gisements présentant des traces d'activité de débitage laminaire est également en cours pour définir s'il s'agit d'ateliers spécialisés ou a contrario de productions domestiques au sein d'habitats. L'étude des séries lithiques, où le débitage de lames est attesté, a été privilégiée pour reconnaitre les chaînes opératoires ayant pu être mises en œuvre, tenter d'en restituer la chronologie et préciser les modalités d'usage de ces productions à partir des contextes et du matériel associé. Dans une perspective plus large, il s'agit de cerner l'ampleur de l'aire de diffusion des lames en silex de Collorgues, et d'évaluer leur importance et leur rôle par rapport aux productions concurrentes. 


\section{GÉOLOGIE ET LITHOLOGIE \\ GÉOLOGIE SOMMAIRE DES ENVIRONS DE COLLORGUES}

Les recherches que nous avons entreprises sur les sites de production de lames des environs de Collorgues nous ont amenés à nous intéresser plus précisément à deux entités géologiques (fig. 1): d'une part le bassin oligocène du Bourdic qui correspond à une plaine légèrement vallonnée où se trouvent la plupart des implantations d'habitats préhistoriques que nous avons pu étudier, d'autre part le plateau éocène d'Aubussargues où se situent les galeries de mines d'extraction du silex (fig. 2). Ce plateau comprend dans sa partie sommitale des niveaux attribuables au Ludien, à «calcaires marneux blanc jaunâtre en bancs réguliers à silex d'environ $20 \mathrm{~m}$ d'épaisseur» (Damiani, 1967, p. 6). La remontée de ce plateau correspond à un double accident tectonique qui est visible dans le paysage: d'une part des accidents alpins de direction nord-est sud-ouest, d'autre part des accidents nord-sud. Ces failles et ces décrochements ont créé des compartiments abaissés ou relevés. Ces différents phénomènes se sont produits pour le plateau d'Aubussargues et les calcaires de Monteils durant l'Oligocène (Damiani, 1967; Berger, 1972). Les bancs de silex exploités par les populations de la fin du Néolithique se trouvent dans les niveaux du Ludien $\mathrm{E} 7 \mathrm{a}^{2}$ de la carte d'Anduze, et E7b de la carte d'Uzès (ibid.).

\section{LA GARACTÉRISATION DU SILEX BRÉCHIQUE DE COLLORGUES}

L'appellation «silex de Collorgues» ou «silex de Collorgues-Aubussargues» est une appellation générique apparue dans la littérature archéologique dans les années 1990. Il correspond au silex lacustre à faciès bréchique présent sous forme de plaques ou de plaquettes dans les niveaux ludiens du plateau d'Aubussargues qui se prolongent à l'ouest par les calcaires de Monteils jusqu'à la commune de Saint-Hilaire-de-Brethmas, à proximité d'Alès.

Les premières mentions dans la littérature sont dues à Émilien Dumas, naturaliste et géologue, qui a établi un inventaire des ressources minérales du département du Gard pour servir à l'industrie (Dumas, 1876). Dans son énumération des ressources siliceuses, on rencontre le silex des environs de Collorgues évoqué dans une rubrique concernant «le silex blond qui est très répandu dans la formation lacustre; il y forme des masses mamelonnées

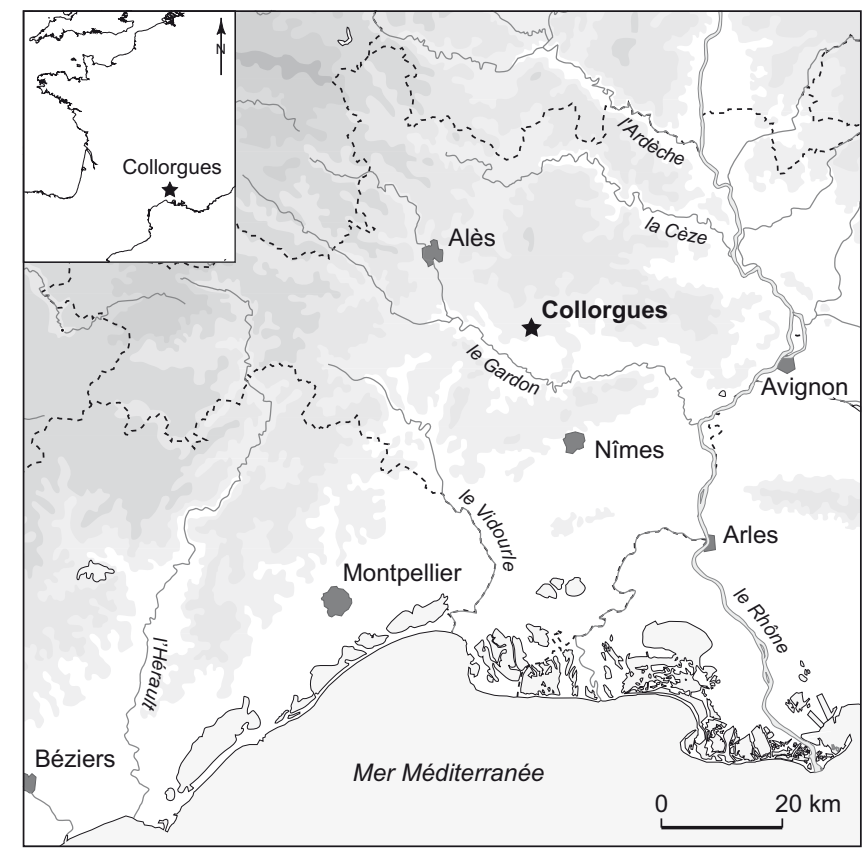

Fig. 1 - Carte de localisation de Collorgues dans le Gard (DAO: M. Remicourt, d'après un fonds de carte Geoatlas).

et souvent des bancs plus ou moins puissants à Salinelles, à Aspères, à Aubussargues, etc. » (Dumas, 1876, vol. 2, p. 705); ou encore dans la description $d u$ «silex pyromaque en plaques ou en rognons aplatis, dont la couleur varie du jaune blond au brun noirâtre. Ces nodules lenticulaires sont souvent très développés et forment alors, au milieu des marnes, de véritables couches subordonnées. Le silex pyromaque se rencontre très abondamment à Salinelles et à Aspères, près de Sommières; dans l'arrondissement d'Alais, à Saint-Hippolyte-de-Caton, à Rivières, à Saint-Privat-deChampclos, à Barjac, etc.; et dans celui d'Uzès, à Garrigues, à Aubussargues, à Saint-Victor-des-Oules, etc. " (Dumas, 1876, vol. 2, p. 511). É. Dumas fait également référence à ce silex pour la production des meules de moulin réalisées à Arpaillargues dans les niveaux du calcaire ludien du plateau d'Aubussargues.

Par la suite, C. Hugues a identifié le silex en plaque utilisé par les populations du Paléolithique moyen de l'Uzège comme provenant du plateau d'Aubussargues (Hugues, 1933) et il fut le premier à affirmer que des mines avaient été exploitées à la fin du Néolithique dans ce territoire (Hugues, 1957; Hugues et al., 1965a et b). Il indiquait que «la région est amplement pourvue de gisements naturels de silex lacustre en plaques plus ou moins épaisses d'excellente qualité, [...], la nature de la matière première dictant 


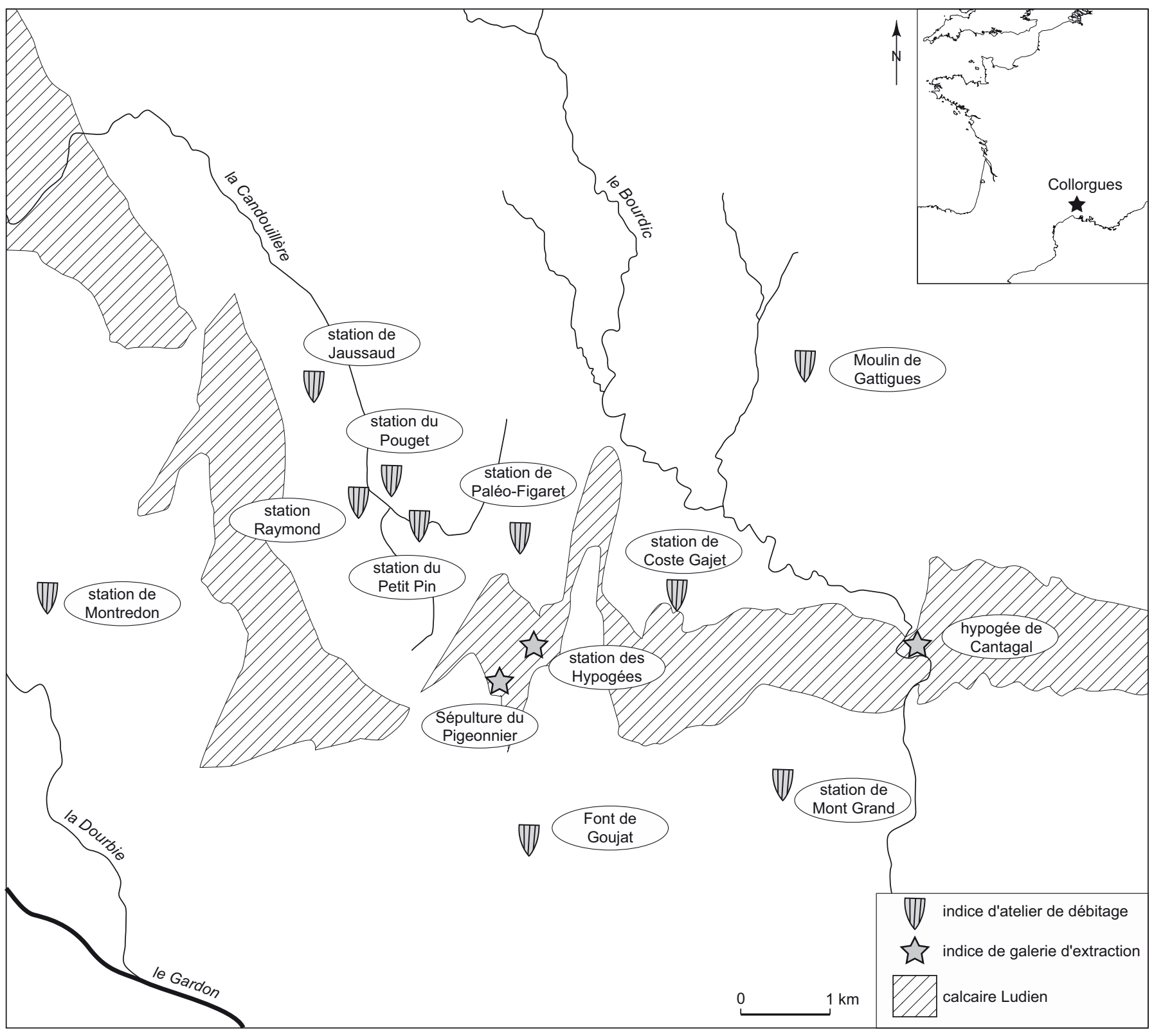

Fig. 2 - Carte de localisation des galeries de mines d'extraction du silex et des ateliers de production laminaire recensés dans les environs de Collorgues, Gard (DAO: M. Remicourt).

souvent sa mise en ouvre» (Hugues et al., 1974, p. 36). Toutefois les descriptions du silex se sont cantonnées à la couleur.

Il a fallu attendre les travaux de F. Bazile sur les séries lithiques régionales pour disposer d'une approche pétrographique de la matière première fondée sur sa reconnaissance macroscopique dans des séries paléolithiques locales (Bazile, 1998 et 2002). Ses études sur l'Aurignacien montrent une production de lamelles sur des plaques en silex ludien du plateau d'Aubussargues selon les modalités d'adaptation au support qu'on retrouvera par la suite à la fin du Néolithique pour les productions laminaires. Les prospections réalisées sur les affleurements de silex de Collorgues-Aubussargues par F. Bazile, C. Bressy et F. Briois ont permis de mieux caractériser les matières premières disponibles et d'individualiser les bancs recherchés pour les productions laminaires de la fin du Néolithique (Bazile et al., 2004; Bressy, 2006). 
Il en ressort que le silex en plaque de $4 \mathrm{~cm}$ à $8 \mathrm{~cm}$ d'épaisseur, exploité pour la production laminaire, est d'aspect bréchique (fig. 3): il s'agit d'une roche formée pour $50 \%$ au moins d'éléments anguleux de dimension inférieure à $0,2 \mathrm{~cm}$ pris dans un ciment siliceux. Elle est polygénique à Collorgues car ces éléments ne sont pas de même nature (Foucault, Raoult, 2000; Bressy, 2006). Selon C. Bressy, il s'agit d'un silex éocène (Ludien inférieur) d'origine lacustre, de couleur marron à gris clair, translucide à opaque, de texture hétérogène de type mudstone à packstone. Il présente des bioclastes (gastéropodes et ostracodes), des lithoclastes hétérométriques et parfois des éléments calcaires. La surface corticale est blanche à blanc-jaune, peu épaisse $(0,2 \mathrm{~cm}$ à $0,5 \mathrm{~cm})$, irrégulière, bioclastique, compacte à pulvérulente. C'est à partir de ces informations et d'échantillons de références que nous avons pu reconnaître cette matière première sur les ateliers de production laminaire et dans les collections archéologiques du Languedoc-Roussillon et de Midi-Pyrénées. Quelques pièces ont également été expertisées par C. Bressy dans les séries de plusieurs sites archéologiques (Le Mourral, Trèbes, Aude; Mas de Vignoles IV, Nîmes, Gard; Montaïon, Sanilhac-et-Sagriés, Gard; Dolmen I de Saint-Martin-duLarzac, Millau, Aveyron; etc.).

\section{LES GALERIES D'EXTRACTION DE SILEX HISTORIQUE DES RECHERCHES}

Le bassin de Collorgues a fait l'objet de nombreuses recherches archéologiques depuis environ un siècle et demi. Les premiers travaux qui ont évoqué de façon indirecte la chaîne opératoire des productions de lames de la fin du Néolithique sont dus à A. Aurès. En 1865, il a fouillé l'Hypogée de Cantagal à Aubussargues, qu'il a décrit "comme une simple grotte sépulcrale recouverte d'une grande dalle»(Bertrand, 1866, p. 202), portée par deux piliers verticaux qui en fermaient l'entrée. Il a découvert à l'intérieur deux grandes salles reliées par un couloir. Cette sépulture collective a livré des fragments de céramique, des armatures de flèche et des lames en silex ainsi que de nombreux ossements dont certains ont été donnés à la Société d'anthropologie de Paris (Bertrand, 1866). Le mobilier céramique de ce site a été attribué aussi bien au Ferrières qu'au Fontbouïsse (Hugues, 1957), de même que celui découvert sur la station de plein air contiguë. Toutefois, les deux dessins de vases cylindriques à cannelures et métopes, comme le signalement d'un poignard et de perles métalliques découverts dans la sépulture, semblent rapporter le contexte funéraire au seul groupe de Fontbouïsse (Lombard-Dumas, 1879). Pour A. Colomer, cette sépulture collective semblait être une réutilisation d'anciennes galeries d'extraction de silex (Colomer, 1979). La présence de céramique du groupe de Ferrières indiquerait une utilisation de la mine dès le Chalcolithique ancien.

Quelques années plus tard, en 1879, la sépulture ou Hypogée de Teste 1 à Collorgues a été mise au jour sur le flanc occidental de la colline de Mas Gaillard (LombardDumas, Rousset, 1887). Cette sépulture collective, qui contenait environ six individus et quatre poignards en silex, a été dégagée par M. Teste et H. Nicolas en 1888 (Nicolas, 1889). La chambre mesurait $1,80 \mathrm{~m}$ de longueur pour $1,50 \mathrm{~m}$ de largeur. Elle était reliée à un couloir en partie effondré à 2,50 m de l'entrée. Les indications et les relevés de H. Nicolas montrent que cette chambre sépulcrale a été fermée par la mise en place de grandes dalles, dont une statue-menhir (fig. $4, n^{\text {os }} 1$ et 3 ). Une seconde statuemenhir se trouvait au milieu des dalles de couverture du couloir (fig. 4, $\mathrm{n}^{\circ}$ 2). À la suite des indications de C. Hugues, J. Arnal a interprété cette chambre sépulcrale comme un ancien puits d'accès pour des galeries de mine suivant les bancs de silex. Elle avait été remployée en sépulture puis condamnée dans un second temps (Arnal, 1959). Cette hypothèse a été admise dans la synthèse sur les hypogées languedociens d'A. Colomer (1979). Les quelques éléments céramiques découverts et les éléments lithiques sont attribuables au groupe de Fontbouïsse. Il faut souligner que deux des poignards signalés sont sur des grandes lames en silex du Grand-Pressigny (Raymond, 1907; Ihuel et al., 2002).

Durant leurs travaux sur l'Hypogée de Teste 1, M. Teste et $\mathrm{H}$. Nicolas ont découvert deux autres galeries de mine à proximité sur la colline du Mas Gaillard, les galeries de Teste 2 et 3 . L'entrée de la galerie 2 s'ouvre à $25 \mathrm{~m}$ de la précédente (Nicolas, 1889). L'entrée était quadrangulaire et recouverte d'une dalle. Elle a été explorée par la suite par les collaborateurs de C. Hugues (Hugues et al., 1965b) qui ont parcouru le réseau en pente, «suivant l'inclinaison des couches géologiques", et qui ont signalés "des bancs de silex au fond des boyaux» (fig. 5). Comme dans le cas des autres galeries, on constate que les parois ont été en partie bâties en pierres sèches. Un pilier de soutènement était présent, sous forme d'une dalle anthropomorphe avec un rostre (Colomer, 1979). Le matériel découvert par C. Hugues, dont un tesson décoré de damiers, a été attribué 


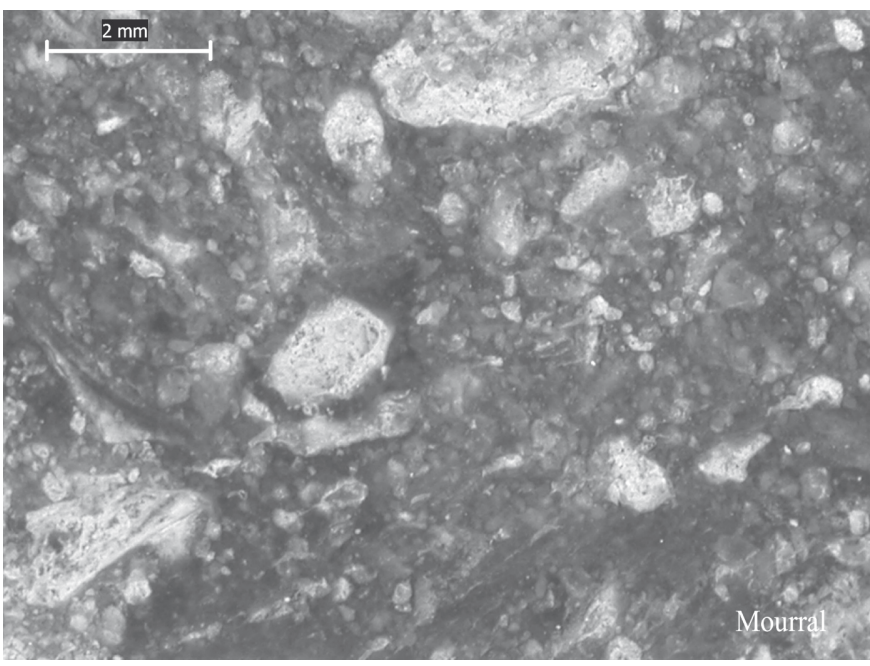

1

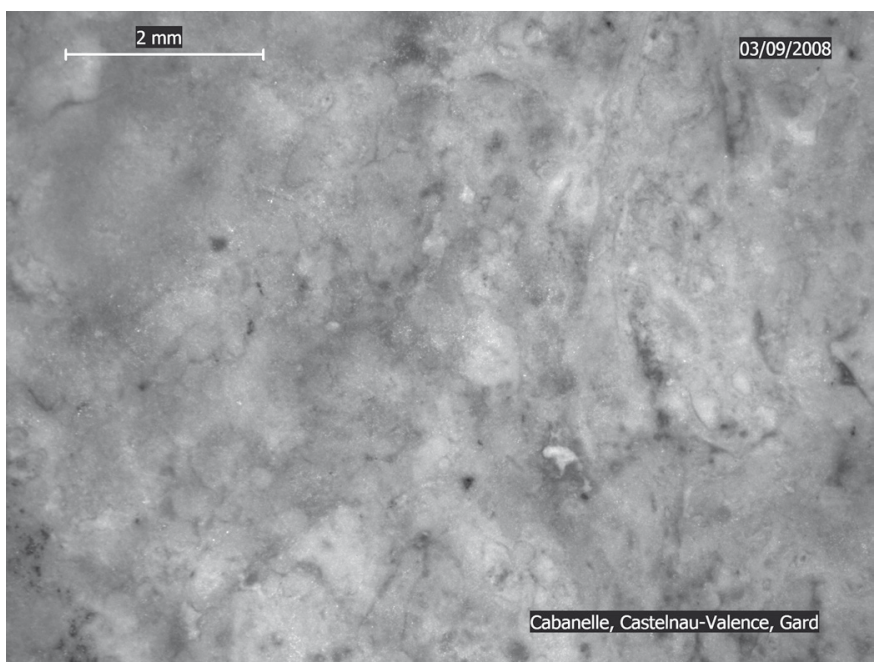

3

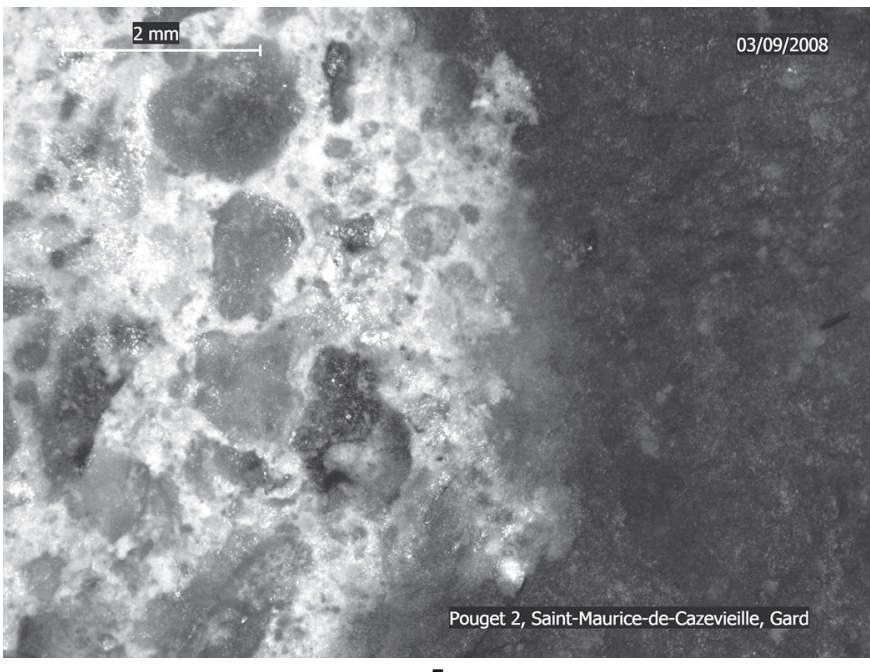

5

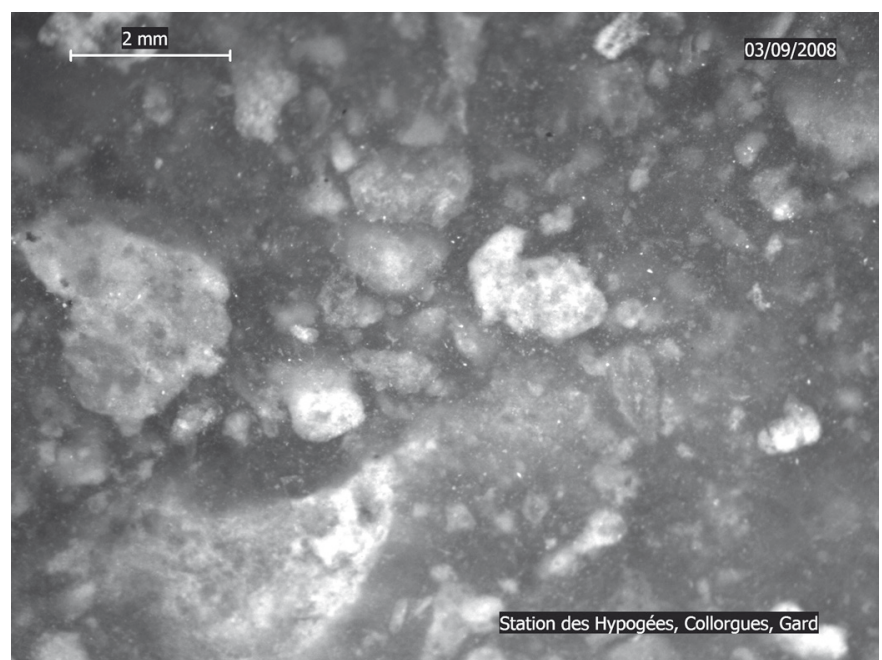

2

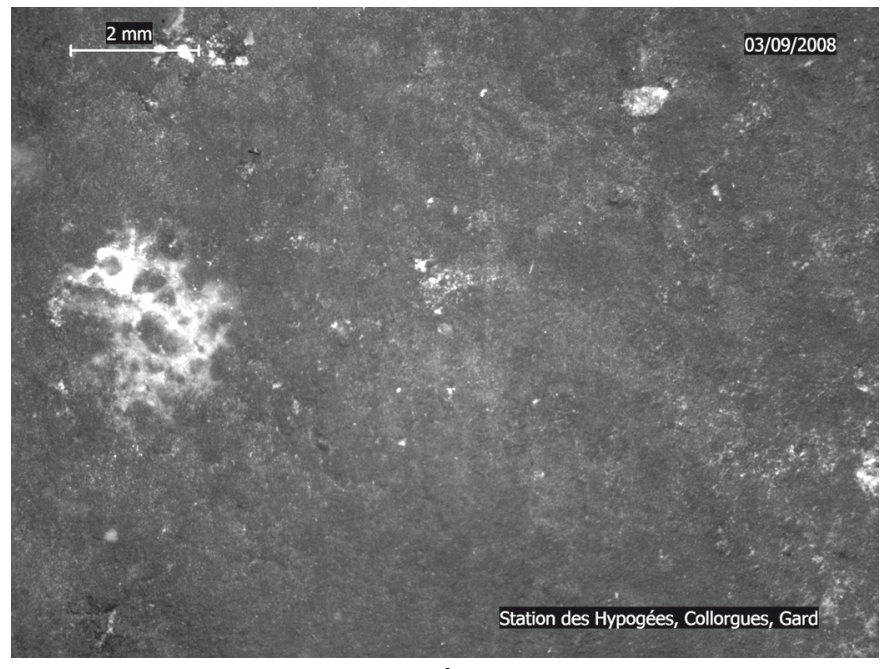

4

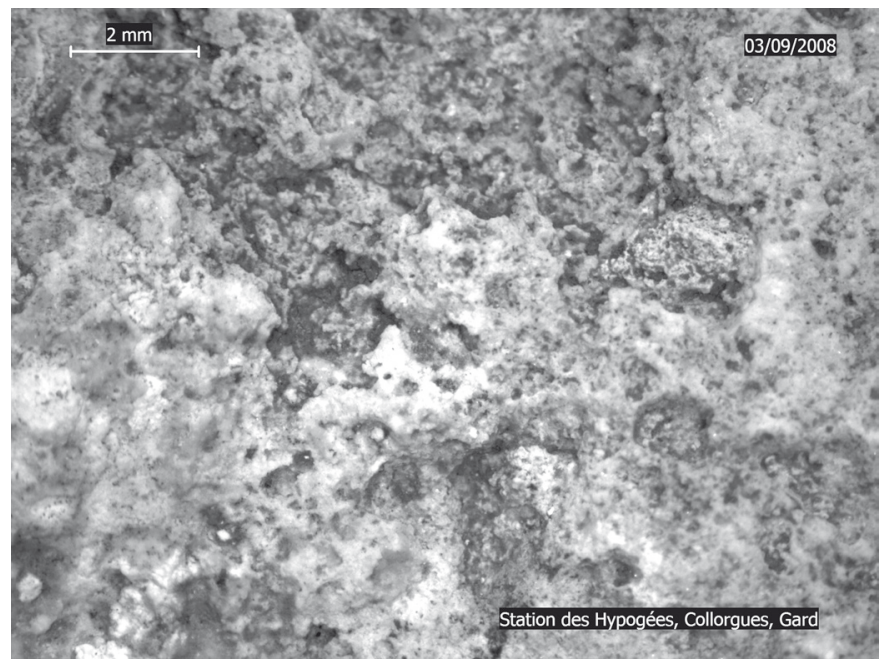

Fig. 3 - Macrophotographies du silex de "Collorgues-Aubussargues». 1: face inverse d'une lame en silex bréchique marron clair, enceinte du Mourral, Trèbes (Aude); 2: échantillon de silex bréchique marron clair, station des Hypogées, Collorgues (Gard); 3 : face inverse d'une lame en silex bréchique patiné blanc, station de Cabanelle, Castelnau-Valence (Gard); 4: échantillon de silex légèrement bréchique marron foncé, station des Hypogées,

Collorgues (Gard); 5 : face inverse d'une lame en silex bréchique à pan cortical, station du Pouget 1, Saint-Maurice-de-Cazevieille (Gard); échantillon de silex bréchique, cortex blanc-jaune, station des Hypogées, Collorgues (Gard) (Clichés: $1 \mathrm{~J}$. Vaquer; 2 à 6 M. Remicourt). 

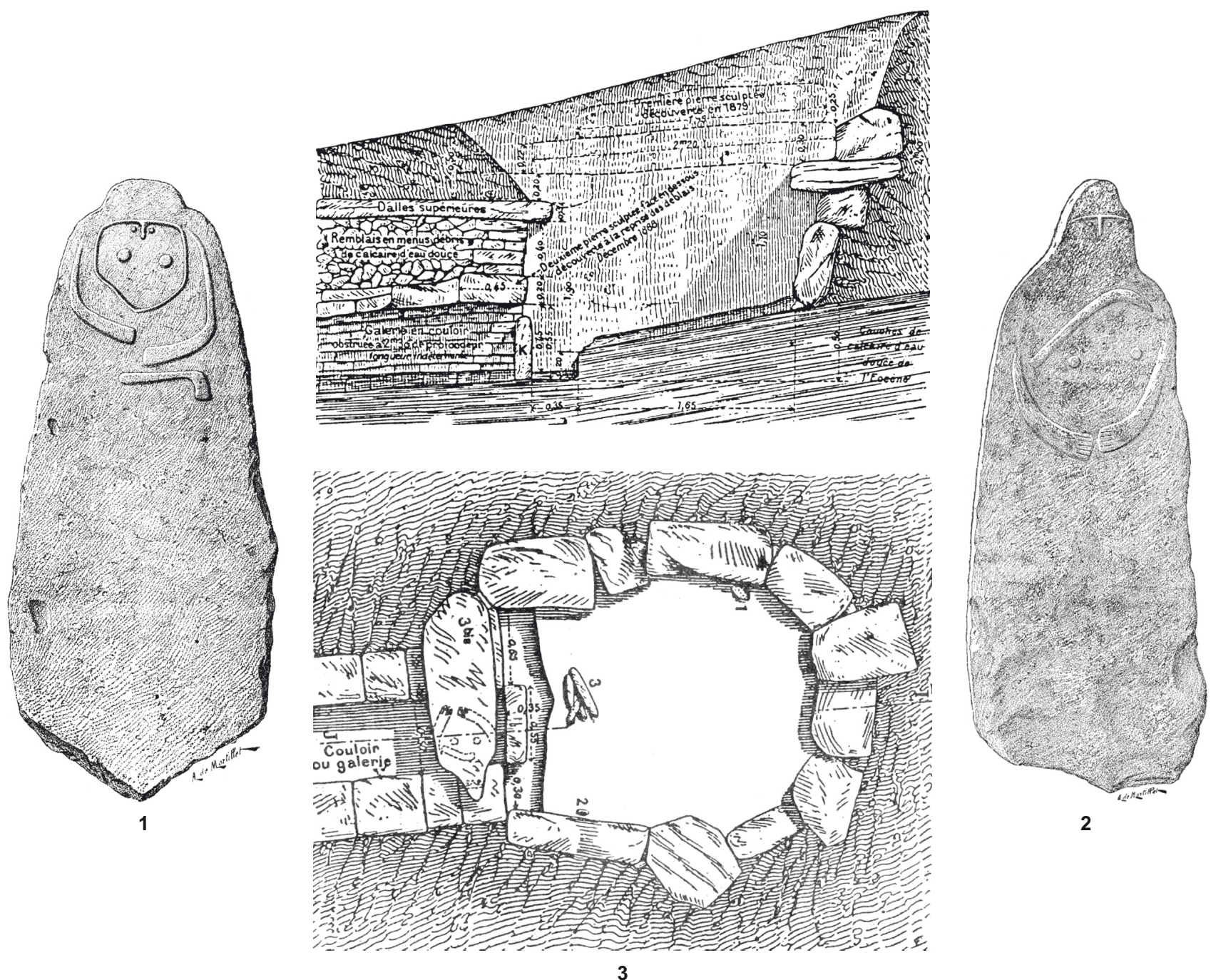

Fig. 4 - «Hypogée » de Teste 1, Collorgues (Gard). 1 et 2: Statues-menhirs découvertes dans le monument (Mortillet 1914); $3:$ Plan et coupe de l'«Hypogée » de Teste 1 (Nicolas, 1889).

au groupe de Fontbouïsse. Une lame en silex a été découverte par H. Nicolas (1889).

La Galerie Durand a été découverte en 1957 par C. Hugues sur la colline du Mas Gaillard (Hugues et al., 1965 a et b). Il s'agissait d'une longue galerie qui n'a pas été totalement explorée à cause des risques d'éboulement. La céramique découverte dans l'entrée a été attribuée au groupe de Fontbouïsse. On note également la présence d'un fragment de lame et d'une pointe foliacée (Colomer, 1979). Pour A. Colomer, la Galerie Durand était sans doute une ancienne entrée de mine pour l'exploitation du silex. Le couloir d'entrée a été bâti en pierres sèches et couvert par des dalles. Le matériel découvert sur la station de Mas Gaillard, au contact de la Galerie Durand, a également été attribué au groupe de Fontbouïsse. Cette station de plein air aurait livré de nombreuses lames et des silex en plaquettes (Hugues et al., 1965a et b). Il s'agissait sans doute d'un atelier de taille, comme l'a proposé C. Hugues qui, d'une manière imagée, a décrit la technique de débitage utilisée par les tailleurs locaux: «le nucléus montre que la lame avait été enlevée comme un copeau dans l'épaisseur d'une plaquette débarrassée de sa gangue sur une face» (Hugues et al., 1965a).

Deux autres structures excavées peuvent être assimilées à des galeries d'extraction de silex. Il s'agit de la Sépulture du Pigeonnier, à Saint-Dézéry, décrite par U. Dumas (1903) comme ressemblant à l'hypogée de la Craie de Foissac. Plusieurs squelettes auraient été trouvés. Une station 


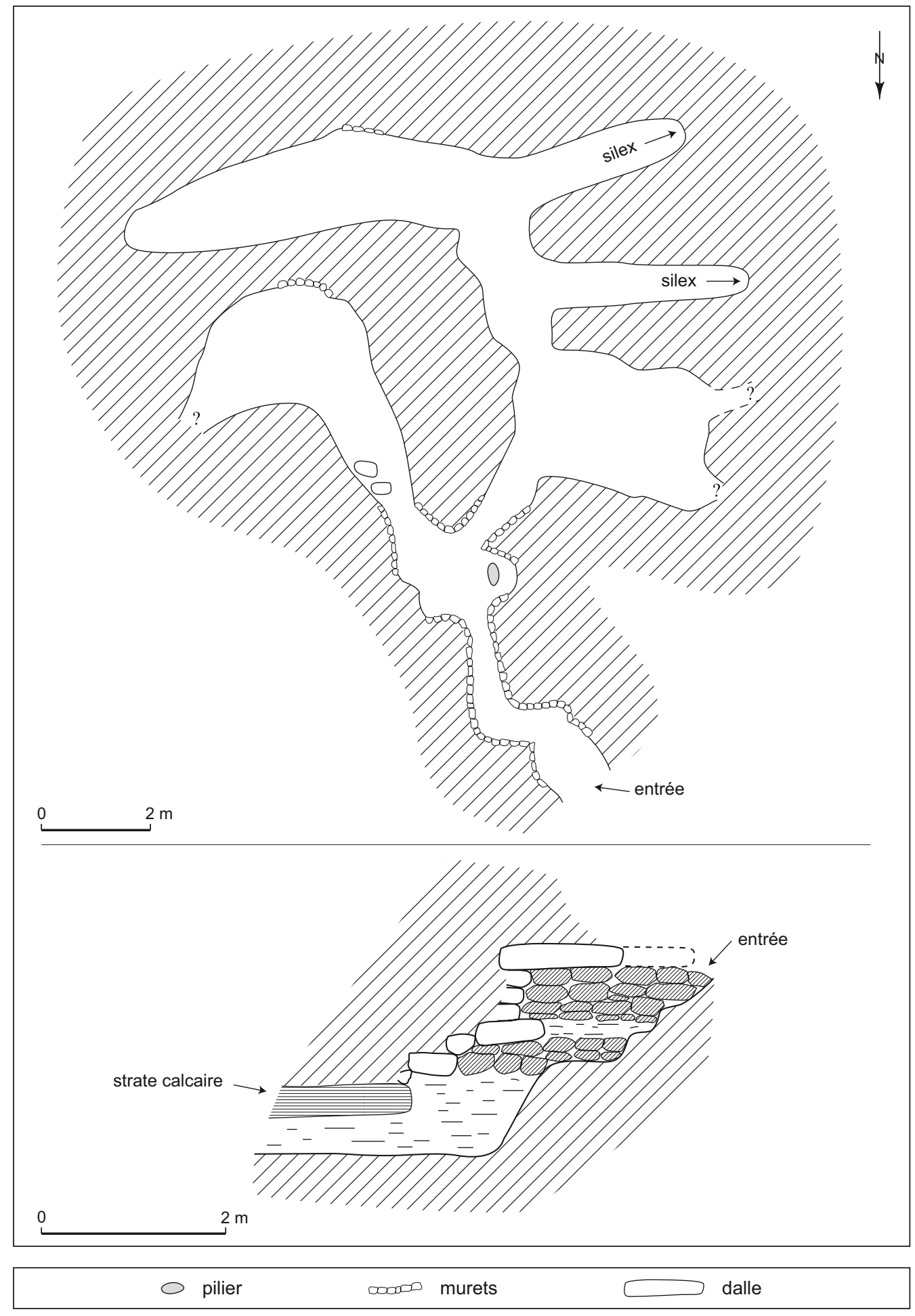

Fig. 5 - «Hypogée » de Teste 2, Collorgues (Gard). Plan et coupe des galeries de mine de Teste 2, d'après Hugues 1965a et b (DAO: M. Remicourt). 
attenante a livré un matériel abondant attribuable au groupe de Fontbouïsse (Bordreuil, 1984). A. Colomer (1979) pense qu'il pourrait s'agir d'une ancienne galerie d'exploitation de silex car, selon la position indiquée par U. Dumas, elle se situe dans les calcaires du Ludien inférieur. Le dernier gisement potentiel est la grotte de la Rouquette, à SaintHilaire-de-Brethmas dans le Gard. Elle a été décrite à la fin du XIX ${ }^{\mathrm{e}}$ siècle par E.-J. Rouverand (1897) qui parle de «l'antre inexploré de la Rouquette» qui «formait une de ces retraites où le troglodyte aime fort à se fixer». Cette sépulture collective a été fouillée par J. Salles en 1948, puis entre 1992 et 1996 (Salles et al., 1950 et 1977; Scimia, Varéa, 1996). Située dans l'étage géologique du Ludien inférieur (Éocène), cette cavité creusée dans une seule strate calcaire forme «un complexe de galeries basses et de culs de sacs, qui ne présente qu'une couche archéologique unique» (Salles et al., 1950). Les parois porteraient des traces de coups. Dans certaines des galeries, on a constaté la présence de murs en pierres sèches, de piliers soutenant les strates supérieures et de grandes dalles de couverture, dont une statue-menhir (Salles et al., 1977; Bordreuil, 1996). Les alentours de la grotte étaient jonchés de silex et plusieurs percuteurs ont été découverts dans la cavité. Le mobilier céramique a été rattaché au groupe de Fontbouïsse, et de nombreux objets en cuivre ont été mis au jour (Salles, Bordreuil, 1965; Scimia, Varéa, 1996).

\section{HYPOTHÈSES SUR LE MODE D'EXPLOITATION DES GALERIES D'EXTRACTION}

Les travaux pionniers de C. Hugues (1965a et b) et de A. Colomer (1979) ont permis de reconnaître le caractère artificiel de ces excavations qui avaient d'abord été interprétées comme des grottes naturelles parfois aménagées pour accueillir des sépultures collectives (Bertrand, 1866; Lombard-Dumas, Rousset, 1887; Nicolas, 1889), voire des dolmens (Mortillet, 1914). À partir des sept structures découvertes et recensées dans la littérature, on peut définir deux types d'exploitation minière qui présentent de nombreuses similitudes.

Le premier type se rattache au modèle de l'Hypogée de Teste 2 (fig. 5) et de la Galerie Durand. Les mineurs ont choisi d'attaquer le flanc de la colline par une galerie en pente ou en escalier pour atteindre les niveaux correspondants aux bancs de silex ludien. Pour contenir les sédiments meubles, les entrées ont été aménagées avec des murs en pierres sèches qui soutiennent de grandes dalles calcaires de couverture. Lorsqu'ils ont atteint les bancs de silex en plaques, les mineurs ont suivi le pendage naturel des strates géologiques, produisant des galeries d'extraction en pente. Des salles ont été aménagées soit en raison de l'extension latérale des bancs de silex, soit pour faciliter les déplacements. Dans le cas de l'Hypogée de Teste 2, l'une de ces grandes salles est prolongée par deux galeries aux extrémités desquelles C. Hugues a indiqué la présence de silex en plaque. Pour soutenir le poids des niveaux supérieurs et sans doute également pour traiter les déblais les plus volumineux issus de l'exploitation minière, ces galeries et ces salles comportent parfois des murs en pierres sèches latéraux. Dans les salles on observe également la présence de piliers de soutènement monolithiques, comme l'exemplaire anthropomorphe de Teste 2 (Colomer, 1979), ou de massifs construits en pierres sèches comme à la grotte de la Rouquette, à Saint-Hilaire-de-Brethmas (Salles et al., 1977).

Le second type se rapproche du modèle d'exploitation découvert à la Vigne du Cade à Salinelles dans le Gard (Peyrolles, 1959; Tamain, 1959), il s'agit de l'Hypogée de Teste 1 à Collorgues (fig. 4). Dans ce cas, la stratégie des mineurs a été de creuser un puits d'accès pour atteindre les bancs de silex en plaques. Ce puits se poursuit par une galerie qui suit les niveaux de silex. On retrouve le même mode de soutènement que dans le premier cas, avec des murs en pierres sèches.

Ces deux types d'exploitation sont sans doute contemporains et sont à mettre en relation avec la morphologie du terrain et l'épaisseur des sédiments à traverser avant d'atteindre les niveaux recherchés.

\section{DE POSSIBLES OUTILS D'EXTRACTION, PERCUTEURS ET MAILLETS À GORGE}

Dans les différents articles traitant des galeries d'extraction, la question de l'outillage des mineurs a été rarement abordée. Nous devons toutefois une étude de ces instruments à M. Bordreuil (1975). Lors des tris des séries issues des prospections de surface, nous avons remarqué de nombreux percuteurs en silex identiques à ceux rencontrés dans les galeries d'extraction de silex ou dans les stations contiguës. Ils appartiennent généralement à des assemblages réunissant de nombreux fragments de lames et des fragments de nucléus laminaires qui nous ont permis de considérer certains sites comme des ateliers. Dans le cas de la station de Jaussaud-Est, à Saint-Maurice-de-Cazevieille, quinze percuteurs ont pu être isolés. Ils sont tirés d'un silex ludien en plaque, de $4 \mathrm{~cm}$ à $6 \mathrm{~cm}$ d'épaisseur, qui correspond au niveau de silex recherché par les mineurs, et présentent tous 

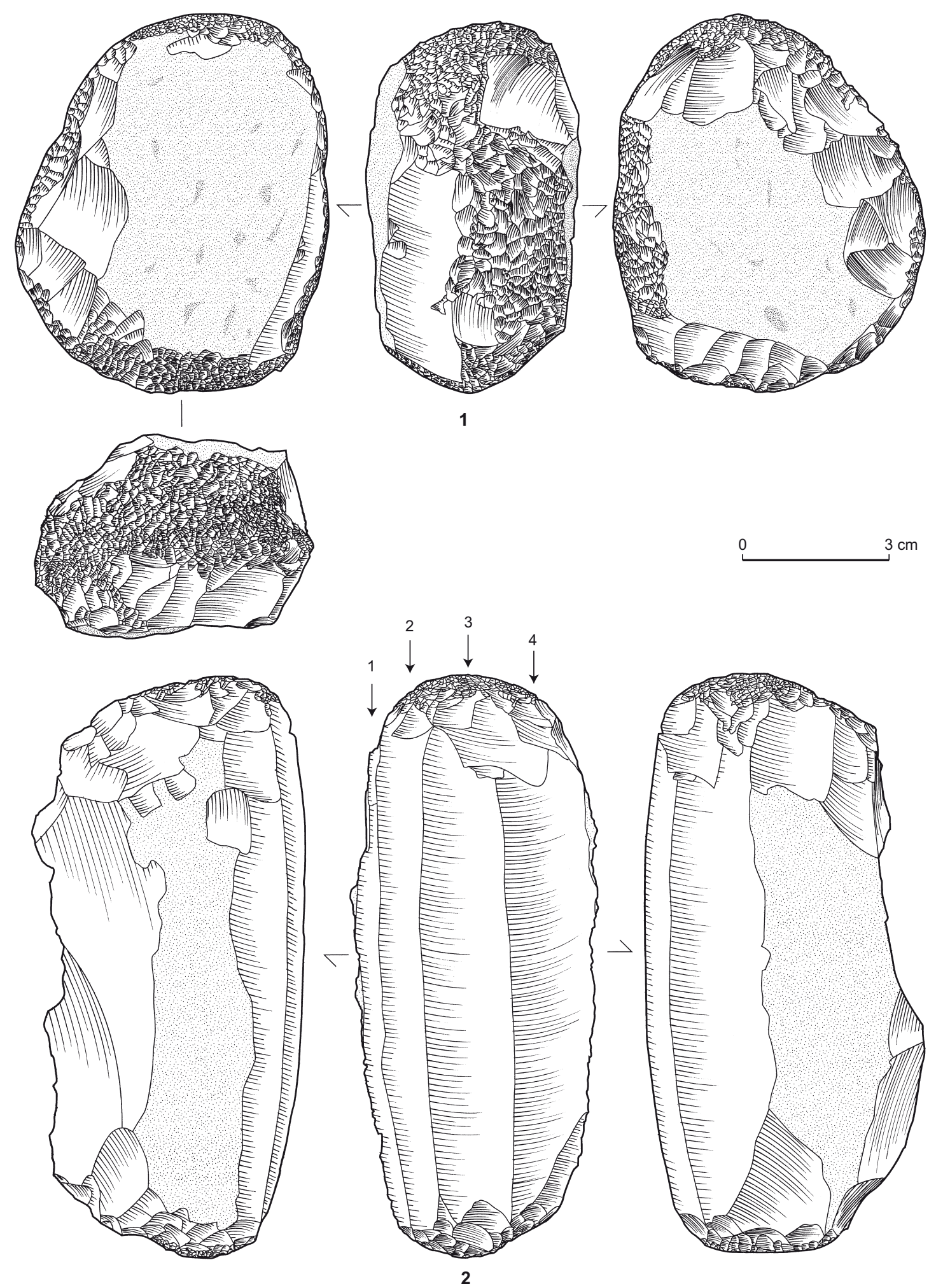

Fig. 6 - Silex bréchique de Collorgues. 1: percuteur sur ancien nucléus laminaire, station de Jaussaud-Est, Saint-Maurice-de-Cazevieille (Gard); 2: nucléus laminaire, station de Paléo-Figaret, Collorgues (Gard). Prospections M. Bordreuil, coll. musée du Colombier, Alès (DAO: M. Remicourt). 
une réserve corticale bilatérale. De forme arrondie à ovoïde, les modules varient entre $5 \mathrm{~cm}$ et $10 \mathrm{~cm}$ de longueur, pour des mensurations quasi identiques en largeur. Ils présentent des stigmates de percussion sur tout le pourtour, tout comme ceux en quartzite des mines de cuivre de Cabrières, dans l'Hérault (Cert, 2005), ou des mines de silex de Salinelles dans le Gard (Briois, 1990). Sur la station de Jaussaud-Est, l'un des percuteurs portait encore le négatif d'un enlèvement laminaire (fig. $6, \mathrm{n}^{\circ} 1$ ), de même que sur la station de Paléo-Figaret, à Collorgues. Sur ce gisement un nucléus laminaire a également été utilisé comme percuteur, à la fois en partie proximale et distale (fig. $6, \mathrm{n}^{\circ} 2$ ). Sur certains percuteurs, on peut identifier les restes d'une crête postérieure qui rappelle le mode de mise en forme employé pour les nucléus à lames. Ces divers indices semblent plaider pour une réutilisation d'une partie des nucléus laminaires comme percuteurs. Ce remploi a d'ailleurs été reconnu sur certains sites d'exploitation de silex, comme à Jablines en Seine-et-Marne (Bostyn, Lanchon, 1992), et expliquerait en partie le faible nombre de nucléus à lames découverts à ce jour dans les environs de Collorgues.

Le second type d'instrument pouvant être lié à l'extraction minière est constitué par des maillets à gorge sur galets en quartzite. Pour le moment, nous n'en avons isolé que deux dont l'un à Jaussaud-Est, mais il en a été signalé à la Vigne-du-Cade, à Salinelles dans le Gard, en relation avec les puits et les galeries d'extraction de silex en plaquette (Colomer, 1979; Briois, 1990). On trouve également des parallèles en Provence avec les fameux maillets de Murs, dans le Vaucluse (Raymond, 1905).

Ces outils, dont l'étude pour en définir l'emploi exact n’a pas encore été entreprise, ont pu être employés pour attaquer le substrat calcaire tendre des niveaux du Ludien inférieur. On ne peut toutefois exclure l'hypothèse d'une utilisation pour piler des minéraux afin de produire du dégraissant pour la céramique ou pour d'autres activités de l'économie domestique de ces groupes. A. Colomer, qui a travaillé sur les galeries d'extraction de silex, nous a toutefois indiqué que de tels outils avaient également été découverts à proximité des lieux d'activités minières, comme à la station des Hypogées, à Collorgues. C. Hugues en a décrit quelques-uns sommairement sur la station de Figaret à Collorgues (Hugues et al., 1974) .

\section{LES ATELIERS DE PRODUCTION DE LAMES}

\section{RECONNAISSANCE DES GISEMENTS}

Malgré les recherches anciennes dans le secteur, les ateliers de production laminaire des environs de Collorgues n'ont été que récemment identifiés. Toutefois, au détour de la littérature, on en trouve des mentions indirectes. Le docteur P. Raymond dans sa monographie sur L'arrondissement d'Uzès avant l'Histoire évoque le canton de Saint-Chaptes avec «les riches stations de Collorgues et d'Aubussargues, dont l'industrie est toute spéciale». Toutefois ce n'est pas tant la production laminaire qui le laisse rêveur, mais plutôt les productions contemporaines sur silex en plaquette où «les pointes de flèche en feuilles de saule ou en amande abondent, remarquables aussi par leur finesse et la perfection de leurs retouches» (Raymond, 1900 , p. 21). Néanmoins, dans l'inventaire des stations néolithiques du Durfortien, qui correspond à l'âge du cuivre cévenol défini par A. Jeanjean (1885), P. Raymond signale quelquefois, sur les gisements qu'il a pu prospecter ou à partir d'informations qu'on lui avait communiquées, la présence parfois importante de fragments de lames (Raymond, 1900, p. 101-107). Pour certaines de ces stations qui ont fait l'objet par la suite de prospections et de ramassages de surface par M. Bordreuil, il ressort qu'il pourrait s'agir d'ateliers de production laminaire, comme dans le cas de la station Raymond à Saint-Maurice-de-Cazevieille (Gard).

C. Hugues a évoqué une possible production laminaire à la station des Hypogées et à la station de Figaret à Collorgues (Hugues et al., 1965a et b et 1974), mais il y voit davantage un débitage aléatoire adapté aux supports de silex en plaque plutôt qu'une production systématisée de produits laminaires standardisés. De plus, une partie de ces lames semblent plutôt correspondre à des éclats laminaires. C'est surtout aux prospections de M. Bordreuil que l'on doit la découverte d'indices d'ateliers correspondant à des fragments de nucléus et de lames, comme celui de PaléoFigaret à Collorgues qui a livré un nucléus à lames bien conservé et un "chalcolithique à lames" (Bordreuil, 1984, p. 224). D'autres prospecteurs actifs dans la région, comme J.-P. Trouillas, ont permis la découverte sur la station du Pouget, à Saint-Maurice-de-Cazevieille, de trois nucléus bien conservés et de nombreux fragments de lames, matériel qui a fait l'objet d'une étude technologique (Briois, 2006). 
Ces divers travaux n'avaient jusqu'alors permis d'identifier formellement que deux ateliers de production laminaire, ce qui paraissait peu au regard de la diffusion des lames de Collorgues. Dans le cadre de la collaboration que nous menons avec M. Bordreuil, nous avons donc entrepris de rechercher, dans les réserves du Musée du Colombier et du Fort Vauban à Alès, les artéfacts issus des ramassages de surface entre Arpaillargues et Saint-Hilaire-de-Brethmas.

\section{LES INDICES D'ATELIERS}

Pour le moment, nos tris ont permis d'identifier dix gisements comme de probables ateliers de production laminaire (fig. 2). Ils sont localisés en contrebas du plateau d'Aubussargues à moins de $3 \mathrm{~km}$ des affleurements ou des lieux d'extraction les plus proches. Le tri des séries ramassées sur le plateau d'Aubussargues et les calcaires de Monteils n'a pour l'instant pas fourni d'indices notables de la présence d'ateliers. Il semble donc que le silex extrait, après un éventuel test ou dégrossissage, était transporté sur les habitats situés dans les vallées, afin d'y être mis en forme et débité en lames. Ce modèle de fonctionnement serait récurrent dans la région pour des raisons de commodité, car C. Hugues remarquait déjà que les implantations paléolithiques dans la région étaient rarement localisées sur les plateaux, mais plutôt dans les vallées et sur les versants moins soumis à l'action du mistral (Hugues, 1933). De plus les vallées sont parcourues par de nombreux cours d'eau et sont beaucoup moins sèches que les plateaux l'été.

La station du Pouget 2, dont une partie du matériel a été étudiée par F. Briois (2006), a donné quelques fragments de nucléus et de lames supplémentaires. Le matériel céramique est attribuable aux groupes de Ferrières et de Fontbouïsse (Bordreuil, 1984). Lors de nos premiers tris, deux stations ont permis une petite étude technologique, le gisement du Moulin de Gattigues à Foissac et la station de Paléo-Figaret à Collorgues. Le matériel appartenant à la première série est issu de divers ramassages effectués par M. Bordreuil, au lieu-dit le Moulin de Gattigues, gisement qui est parfois signalé sur la commune limitrophe d'Aigaliers (Gisclon, 1982). On note la présence de plusieurs types de silex, en plus du silex ludien bréchique qui constitue la majeure partie de la collection. On reconnaît une variété de bois fossile silicifié également présent sur d'autres gisements des environs, ainsi qu'un silex blond-miel à grain fin et nombreuses inclusions à cortex non roulé correspondant au silex du Cénomanien disponible à proximité (Dumas, 1876; Boccaccio, 2005). Les prospections de M. Bordreuil ont également révélé des fragments de meules et des restes fauniques. La céramique est attribuable exclusivement au groupe de Fontbouïsse (Gisclon, 1982). Le gisement de Paléo-Figaret à Collorgues a été découvert par M. Bordreuil en tête du ruisselet de la Roubine, à proximité de la station de Figaret fouillée par C. Hugues (Hugues et al., 1974). La station de Paléo-Figaret est située entre une station moustérienne et une station du Bronze final. On constate la présence d'ossements d'animaux et de matériel de mouture. Le matériel céramique est attribuable au groupe de Ferrières et au groupe de Fontbouïsse (Bordreuil, 1984; Gisclon, 1982). Le matériel lithique est représenté par un grand nucléus laminaire et des fragments de lames.

Les autres ateliers détectés se sont révélés moins riches en matériel; toutefois les différents indices que constituent les fragments de nucléus laminaires, de lames et les percuteurs ovoïdes en silex étaient présents, ce qui nous a permis de les retenir pour notre étude. La commune de Saint-Mauricede-Cazevieille a livré plusieurs ateliers potentiels. Il s'agit de la station de Jaussaud-Est, qui est surtout connue pour son occupation cardiale (Bordreuil, 1982; Gisclon, 1982) et où ont été découverts une quinzaine de percuteurs sur silex en plaque et un maillet à gorge en quartzite, une vingtaine de fragments de lames et trois fragments de nucléus laminaires en silex ludien. La céramique attribuable au Chalcolithique correspond au groupe de Fontbouïsse. La station Raymond est un gisement découvert par le docteur P. Raymond à la fin du XIX ${ }^{\mathrm{e}}$ siècle. Elle a livré deux fragments de nucléus laminaires et quelques lames en silex de Collorgues. Sur la commune de Collorgues, outre Paléo-Figaret, on distingue la station du Petit-Pin qui a fourni pour sa part une dizaine de percuteurs sur silex en plaque, quinze fragments de lames et deux fragments de nucléus laminaires. La céramique est attribuable aux deux groupes régionaux du Chalcolithique (Bordreuil, 1984; Gisclon, 1982). On trouve quasiment les mêmes données à la station de Coste-Gajet à Collorgues, à la station de Mont-Grand à Garrigues et à celle de Fontde-Goujat à Saint-Dézéry. La station de Montredon, à Castelnau-Valence, a été découverte lors d'un défoncement qui a disloqué plusieurs cabanes en pierres sèches. Un fragment proximal de lame en silex du Grand-Pressigny y a été mis au jour. La céramique est attribuable au Ferrières et au Fontbouïsse (ibid.). Deux percuteurs en silex en plaque ont pu être isolés, ainsi que trois fragments de nucléus laminaire et une quinzaine de fragments de lames.

Malgré des effectifs restreints, cette première révision montre qu'il existe un potentiel à exploiter. Le faible nombre de pièces s'explique par leur collecte en surface, 
pour l'essentiel dans des vignobles rarement labourés profondément.

\section{LES SÉRIES LITHIQUES DES ATELIERS}

Nous présenterons ici succinctement les données obtenues à partir du matériel du Moulin de Gattigues à Foissac, de Paléo-Figaret à Collorgues et les nucléus et fragments de nucléus de façon générale.

\section{LE MATÉRIEL LAMINAIRE}

\section{Le site du Moulin de Gattigues à Foissac}

La série collectée par M. Bordreuil comprend 71 fragments de lames et 4 fragments de nucléus laminaires (fig. 7-8). La moitié des fragments de lames sont à bord cortical (47,9\%), tirées d'un flanc du nucléus. Les lames portant des traces de mise ou de (re)mise en forme du nucléus sont également bien représentées dans la série $(28,1 \%)$. En revanche, les fragments de lames de plein débitage sont largement déficitaires par rapport aux pièces dites techniques. Les lames mesurent en moyenne $1,87 \mathrm{~cm}$ de largeur et $0,67 \mathrm{~cm}$ d'épaisseur. Les talons sont majoritairement lisses et forment un angle de bord un peu inférieur à $90^{\circ}$, les bulbes sont généralement marqués et la face inférieure ondulée. Les nervures sont sinueuses. La préparation de la corniche indique une abrasion et des enlèvements microlaminaires pour amincir la zone dévolue au talon. Les talons ont une mesure moyenne de $0,5 \mathrm{~cm}$ sur $0,2 \mathrm{~cm}$ $(\mathrm{n}=16)$.

Le diagramme des largeurs en fonction des épaisseurs des lames montre que la production est comprise principalement entre $1,5 \mathrm{~cm}$ et $2,5 \mathrm{~cm}$ de largeur; toutefois les produits de plein débitage à section triangulaire offrent une dispersion moindre. La présence de lames plus étroites $(<1,5 \mathrm{~cm}$ de largeur) est sans doute liée au reste de la production laminaire et ne correspond pas à une production spécifique. Ces produits plus petits ont parfois été exportés comme le montrent quelques pièces découvertes sur des sites dans un rayon d'une vingtaine de kilomètres autour des ateliers, telle la petite flèche foliacée sur lame en silex de Collorgues $(3,1 \mathrm{~cm}$ x $1,1 \mathrm{~cm}$ x 0,4 cm) de la station de Combe Raymonenque à Saint-Jean-de-Maruéjols (Gard).

L'un des points intéressants à souligner est la faible représentation des produits de plein débitage $(19,71 \%)$ par rapport aux lames latérales à bord cortical ou sous- crête $(76,05 \%)$. De plus, le nombre de produits laminaires retouchés est infime.

\section{Le site de Paléo-Figaret à Collorgues}

La série de Paléo-Figaret comporte 48 fragments de lames, 5 fragments de nucléus laminaires et un exemplaire presque entier (fig. 8-9). Comme dans le cas précédent, on constate une prédominance des lames à bord cortical (52\%), toutefois les fragments de lames avec traces de (re) mise en forme sont moins fréquents $(14,5 \%)$. Les fragments de lames de plein débitage sont moins représentés que les pièces techniques $(31,5 \%)$. La moyenne générale des largeurs des fragments de lames donne 2,07 cm, celle des épaisseurs $0,71 \mathrm{~cm}$. Ces mensurations plus larges et plus robustes sont à corréler avec la moindre présence des petits éléments laminaires tels ceux du Moulin de Gattigues. Comme sur ce gisement, les talons sont majoritairement lisses et légèrement inclinés. Les talons ont une mesure moyenne de $0,9 \mathrm{~cm}$ pour $0,25 \mathrm{~cm}(\mathrm{n}=17)$. La préparation de la corniche est surtout marquée par l'utilisation de l'abrasion, l'association avec les enlèvements microlaminaires étant présente de manière sporadique. Les bulbes sont marqués, la face inférieure ondulée et les nervures sont sinueuses.

Les produits mesurent principalement de $1,5 \mathrm{~cm}$ à $2,5 \mathrm{~cm}$ de largeur, et plus de $2 \mathrm{~cm}$ pour la plupart des lames à section trapézoïdale. Comme dans le cas précédent, on observe une opposition entre les produits à bord cortical et sous-crête $(66,6 \%)$ et les lames de plein débitage au sens large $(31,5 \%)$. On constate que presque aucun fragment de lame ne porte de traces de retouche.

\section{Comparaison des deux gisements}

Malgré un effectif restreint, ces deux séries montrent des similitudes dans les modes de production, avec l'utilisation de la percussion indirecte sur des nucléus sans doute «en mitre», une préparation par enlèvements microlaminaires et abrasion de la corniche, des talons préférentiellement lisses, des productions avec des mensurations proches pour les largeurs et les épaisseurs. Dans les deux cas, on constate un déficit des produits de plein débitage qui est sans doute la traduction d'un tri de la production pour l'exportation ( $c f$. infra, p. 237). Les légères différences que l'on note quant aux parties proximales entre les deux séries ne permettent pas vraiment de faire de propositions objectives. Toutefois elles ressortent dans la préparation des corniches. À Paléo- 

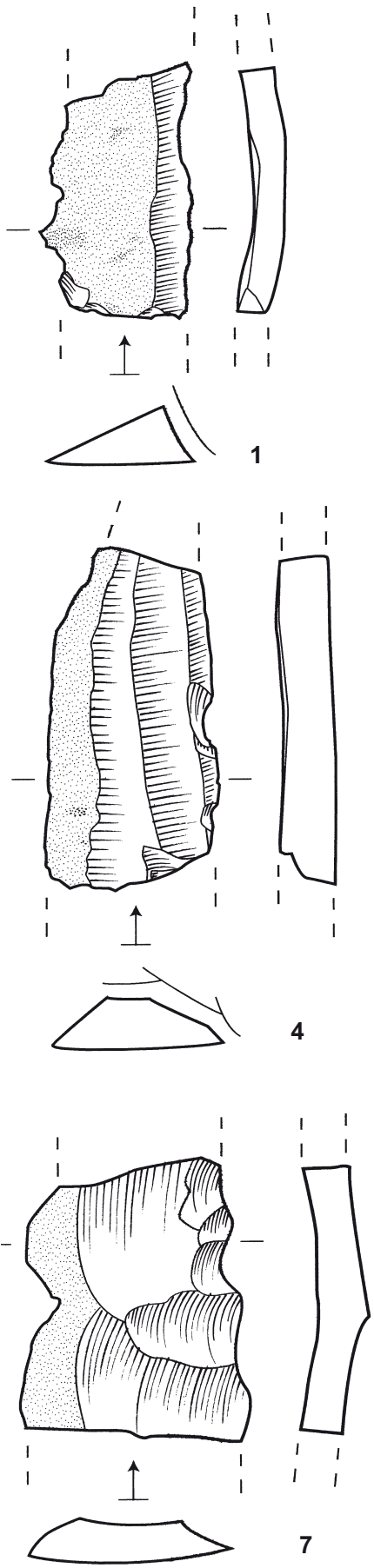
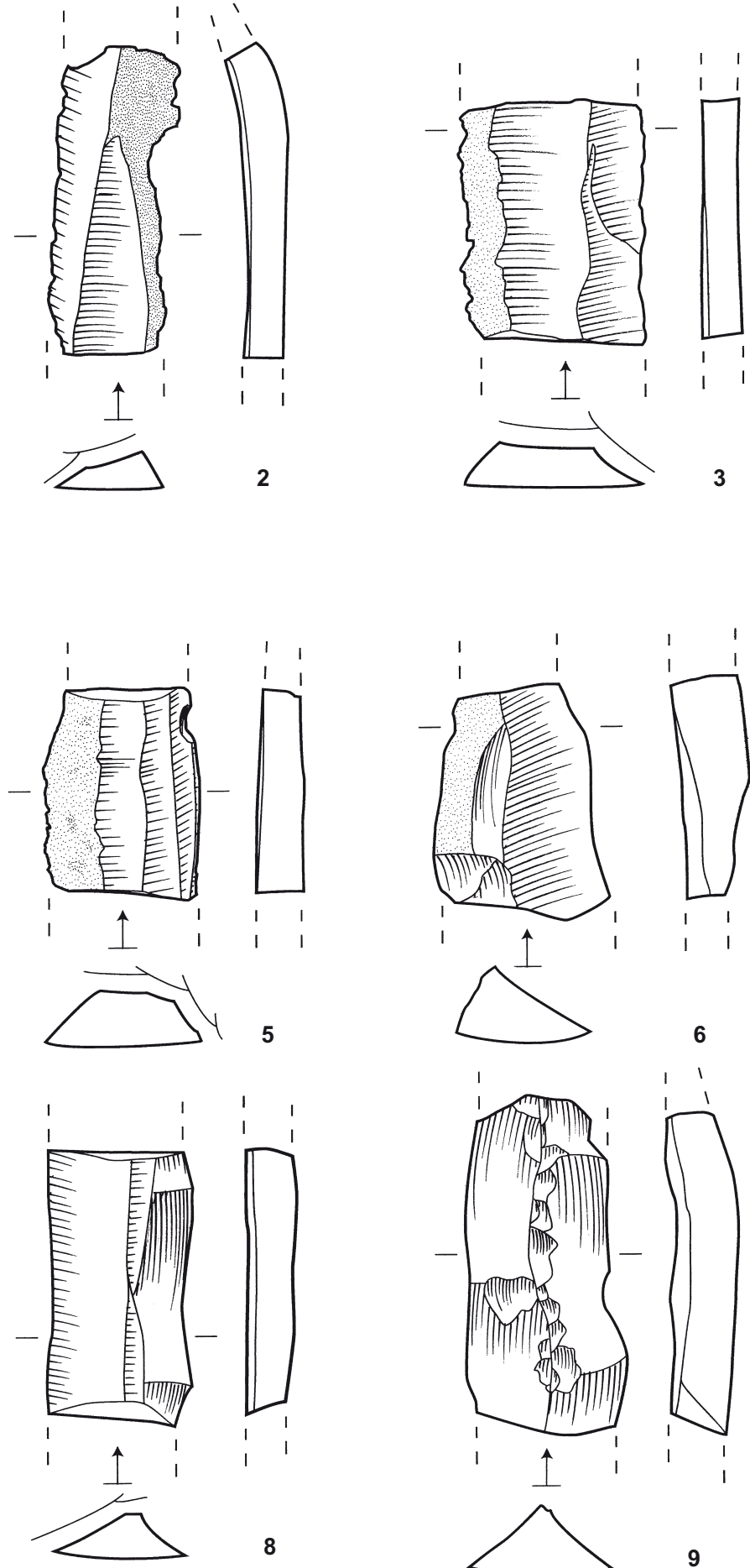

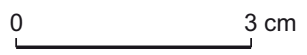

Fig. 7 - Silex bréchique de Collorgues. Exemples de fragments de lames découverts sur l'atelier de production laminaire de la station du Moulin de Gattigues, à Foissac (Gard). Prospections M. Bordreuil, coll. musée du Colombier, Alès (DAO: M. Remicourt). 


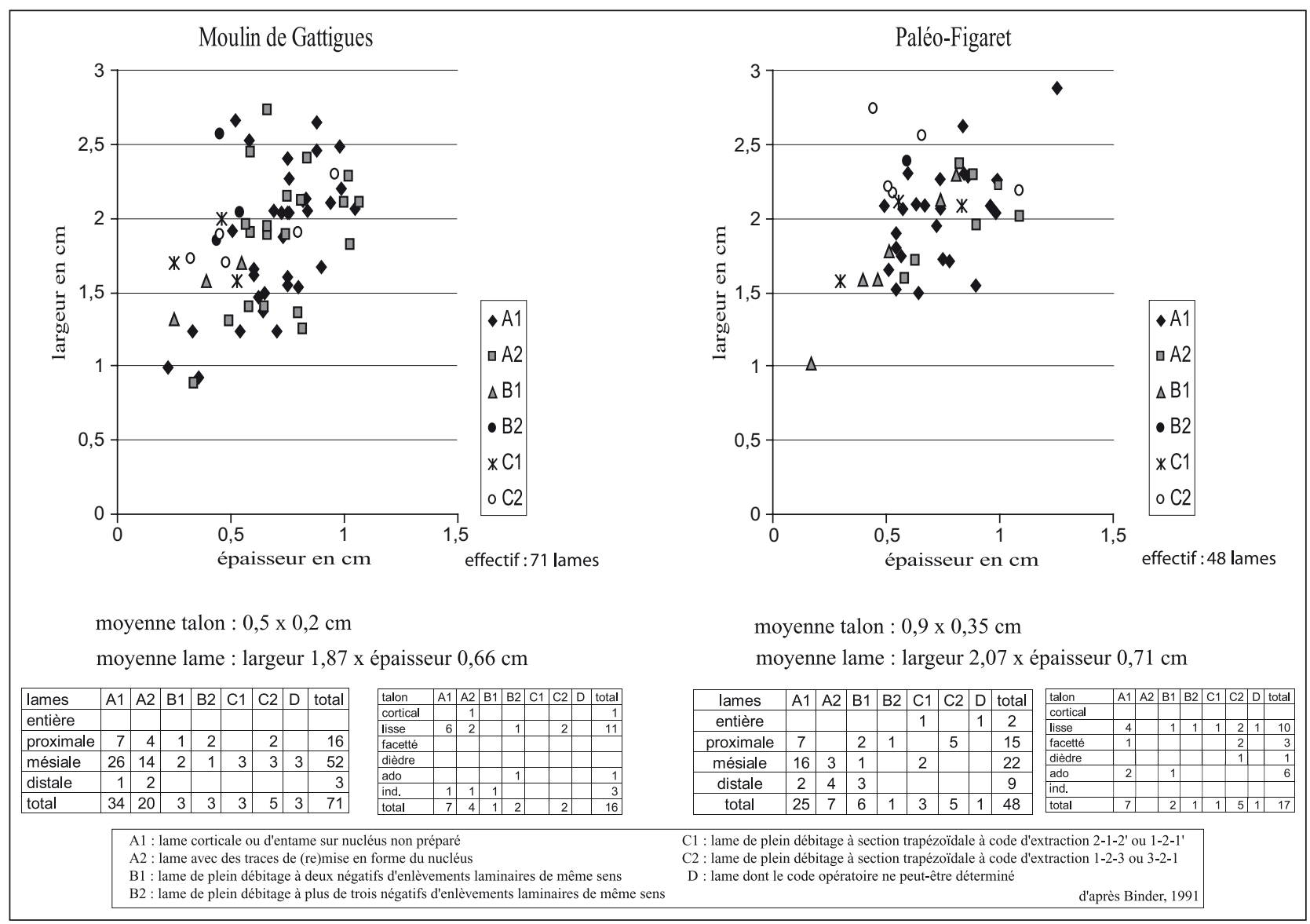

Fig. 8 - Morphométrie et classement technologique des lames découvertes sur les ateliers de Paléo-Figaret à Collorgues et du Moulin de Gattigues à Foissac (Gard) (DAO: M. Remicourt).

Figaret, on constate un recours quasi spécifique à l'abrasion, les enlèvements microlaminaires étant plus aléatoires alors que ces deux techniques sont toujours conjuguées au Moulin de Gattigues. Ce traitement entraîne des modules moyens de talons plus petits au Moulin de Gattigues qu'à Paléo-Figaret et, par voie de conséquence, des productions laminaires plus graciles. Il n'est pas encore possible de dire si cette différence est d'ordre chronologique, Paléo-Figaret pouvant être plus ancien que le gisement de Moulin de Gattigues attribuable au groupe de Fontbouisse, ou s'il s'agit seulement de modes opératoires légèrement différents entre deux groupes contemporains, qui constitueraient une sorte de signature d'atelier.

\section{LES NUGLÉUS LAMINAIRES}

Les critères technologiques observés sur les fragments de nucléus laminaires recueillis sur les ateliers vont dans le sens des observations faites par F. Briois à partir des nucléus entiers du Pouget à Saint-Maurice-de-Cazevieille (2006). L'élément le mieux conservé que nous avons pu isoler provient de la station de Paléo-Figaret, à Collorgues (fig. 6, $\mathrm{n}^{\circ}$ 2). Il s'agit d'un nucléus quasi entier, dont les deux extrémités sont arrondies par son utilisation comme percuteur, empêchant toute lecture du plan de frappe et de l'extrémité opposée du nucléus. Ses mensurations actuelles sont $12,5 \mathrm{~cm} \times 6,14 \mathrm{~cm} \times 5,17 \mathrm{~cm}$. L'épaisseur de la plaque de silex utilisée $(5,17 \mathrm{~cm})$ est similaire à celle des nucléus du Pouget. Les négatifs de la surface de débitage traduisent un débitage tournant, avec des négatifs d'enlèvements laminaires débordants sur les deux côtés. Les nervures sont légèrement sinueuses. On constate la mise en place d'une crête postérieure à peu près centrée par enlèvements bifaciaux.

Toutefois, dans les ateliers, l'essentiel des indices traduisant la présence des nucléus laminaires et permettant d'autres observations est donné par de gros débris ou par 


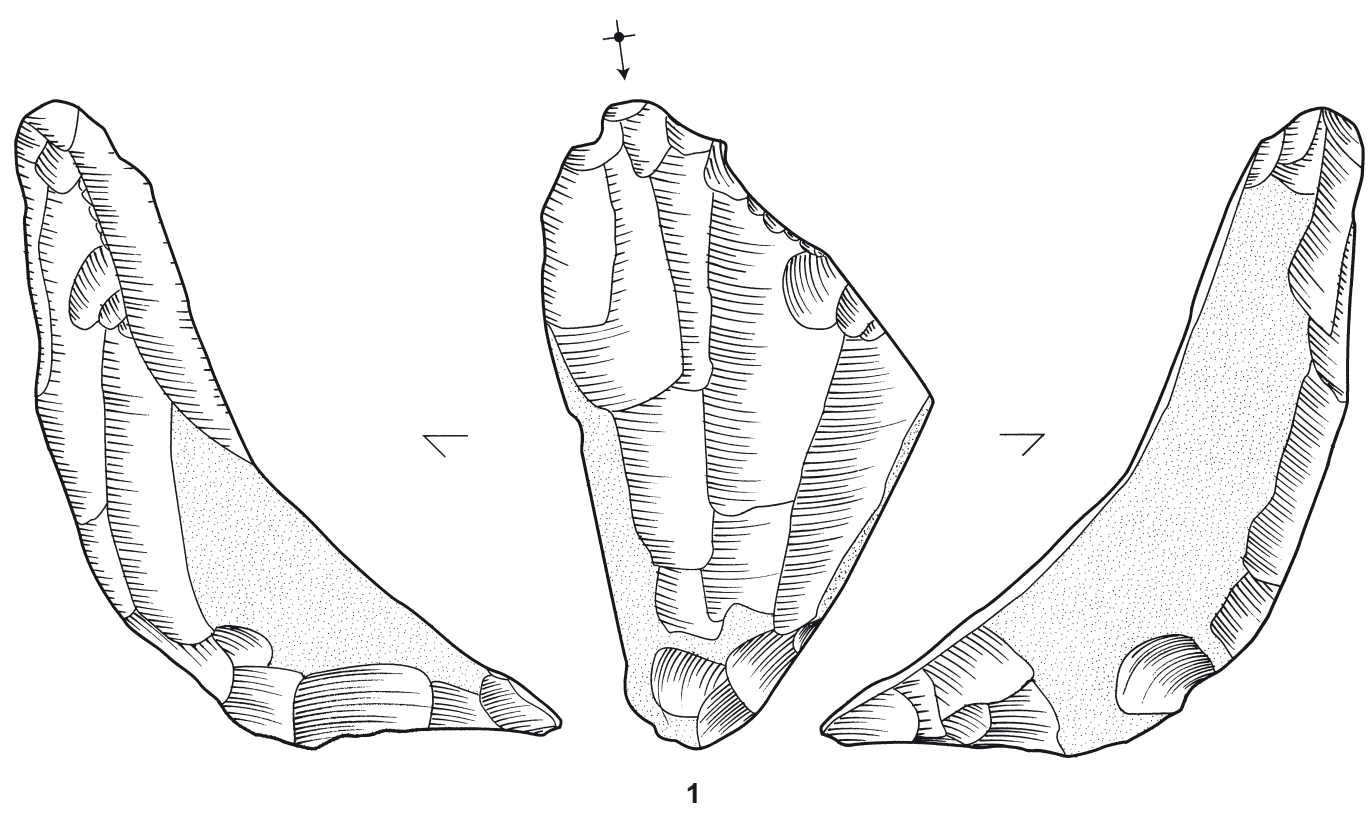

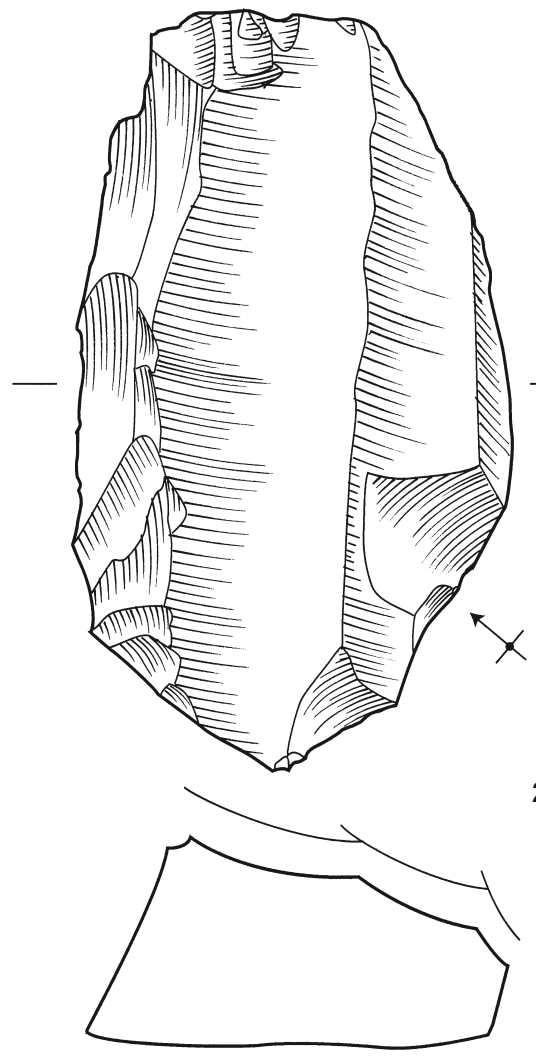

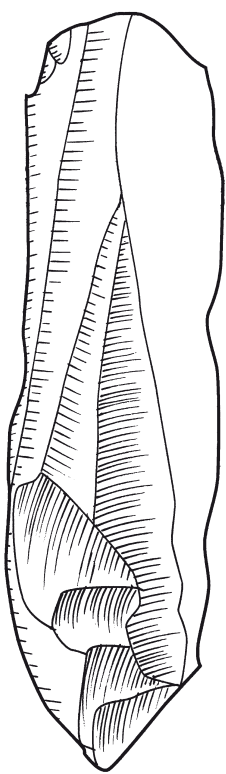

des éclats obtenus par percussion directe et issus d'une reprise ultérieure en nucléus à éclats. L'étude de ces éclats montre les divers critères observés sur les nucléus bien conservés. La préparation du plan de frappe par abrasion et

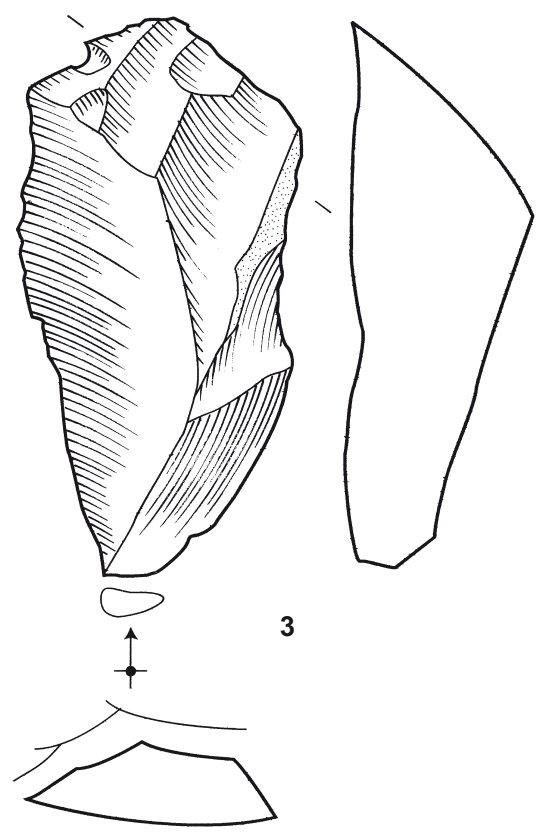

Fig. 9 - Silex bréchique de Collorgues. Fragments de nucléus laminaire. 1: station de Font-de-Goujat, Saint-Dézéry (Gard); 2: station Raymond, Saint-Maurice-de-Cazevieille (Gard); 3, station de Paléo-Figaret, Collorgues (Gard). Prospections M. Bordreuil, coll. musée du Colombier, Alès (DAO: M. Remicourt).

enlèvements microlaminaires est visible sur un grand éclat laminaire de la station de Coste-Gajet à Collorgues. On retrouve les traces de préparation ou de remise en forme latérale du nucléus sur l'un des éclats de la station Raymond 
à Saint-Maurice-de-Cazevieille, et sur deux fragments de partie distale de nucléus à la station de Font-de-Goujat à Saint-Dézéry. On constate une série de petits enlèvements obliques et opposés, formant une crête inférieure et rétrécissant cette zone, comme dans le cas des pièces entières du Pouget. Il semble y avoir une prédominance du débitage semi-tournant, que ce soit sur des fragments de nucléus de Paléo-Figaret ou de la station Raymond. Les derniers négatifs d'enlèvements laminaires montrent que les produits se situent autour de $2 \mathrm{~cm}$ de largeur (fig. 9).

L'observation des lames avec des traces de (re)mise en forme du nucléus montre que, si la majorité des enlèvements pour la préparation de la crête sont d'origine antéro-latérale, certains enlèvements en partie distale sont d'origine postéro-latérale. On remarque également certaines pièces à réserve corticale centrale, entre deux négatifs d'enlèvements sur le gisement de Paléo-Figaret à Collorgues, ainsi qu'au Trou du Loup à Armissan dans l'Aude (Briois, 2005, fig. 176, $\mathrm{n}^{\circ}$ 2). Ces exemples suggèrent qu'il pourrait exister dans certains cas une préparation minimale du nucléus, avec seulement un aménagement du plan de frappe et de la partie distale pour dégager une préforme cintrée, une partie de la table de débitage pouvant être laissée brute ou aménagée sommairement sans mise en place d'une crête sur toute la longueur. Ce pourrait être une adaptation à une morphologie adéquate de la plaque de silex, dont le tailleur n'a préparé que le plan de frappe, la partie distale ainsi que la crête postérieure du nucléus.

\section{PROPOSITION D'UN MODÈLE D'EXPLOITATION}

Ces différentes observations permettent d'élargir le schéma opérationnel proposé par F. Briois à partir de la série du Pouget. Les plaques de silex sont mises en forme par l'aménagement d'un plan de frappe par décalottage de la partie supérieure, la future surface de débitage convexe et légèrement cintrée est aménagée en crête par enlèvements bifaciaux antéro-latéraux, prolongée par une pseudo-crête plus fruste dans la partie postérieure du nucléus, lui donnant ainsi une forme «en mitre». Le débitage des lames est effectué par percussion indirecte (Briois, 2006). Il est débordant sur les côtés, ce qui permet d'optimiser la production de lames de plein débitage. On observe des traces de remise en forme du nucléus sur les lames et sur certains fragments de nucléus laminaires qui sont liés à la maîtrise du gabarit du nucléus au cours du débitage (fig. 10). Ce débitage semble être majoritairement semi-tournant. Ces nucléus ont été recyclés comme percuteurs, ou repris par percussion dure directe pour une production d'éclats. Ce débitage d'éclats pourrait donc également être lié à la mise en forme des percuteurs.

On peut essayer de déterminer le taux de lames de plein débitage à partir des exemples que nous connaissons. Ainsi le nucléus de Paléo-Figaret et ceux du Pouget suggèrent une production de trois lames dont au moins une de plein débitage à chaque série, voire de quatre lames dont au moins deux de plein débitage. Les lames de plein débitage devraient représenter au minimum entre $33 \%$ et $50 \%$ des pièces dans les séries des ateliers. Le déficit que l'on peut observer est donc dû à une sélection des pièces de plein débitage qui ont été exportées.

\section{DIFFUSION DES PRODUCTIONS LAMINAIRES EN SILEX DE COLLORGUES}

Les productions laminaires en silex de Collorgues ont été largement diffusées durant tout le Néolithique final et le Chalcolithique sur le pourtour méditerranéen tant languedocien que roussillonnais et sur les Grands Causses (fig. 11, 12 et 13). Toutefois cette réalité n'a été que récemment perçue pour les produits découverts à longue distance avec les travaux de F. Briois (2005 et 2006) et de J. Vaquer (Vaquer et al., 2006a, b, c et à paraître). Elle a été permise par le développement des connaissances sur les microfaciès des matières premières siliceuses et par la prise en compte de celles-ci par les archéologues. Dans les environs de Collorgues, la diffusion locale de ces produits a été reconnue beaucoup plus tôt, comme dans le cas du poignard foliacé sur lame de la grotte I du Galinier, à SaintJean-de-Maruéjols dans la vallée de la Cèze (Gard), dont l'origine a été attribuée «au silex marbré de Saint-Mauricede-Cazevieille» (Bordreuil, 1992, p. 38).

\section{LES SÉRIES LITHIQUES DANS LES ENVIRONS PROCHES ET LA PLACE DES LAMES EN SILEX DE COLLORGUES}

La recherche des ateliers de production de lames nous a amenés à examiner de nombreuses séries lithiques de stations de plein air attribuables à la fin du Néolithique des environs de Collorgues. Il ressort que les industries laminaires sont peu, voire pas représentées. Les spectres sont dominés par une production d'éclats par percussion dure directe ou par percussion sur enclume, comme dans le cas des séries lithiques contemporaines que nous avons pu étudier dans le Gard (grotte du Taï à Remoulins, grotte de 


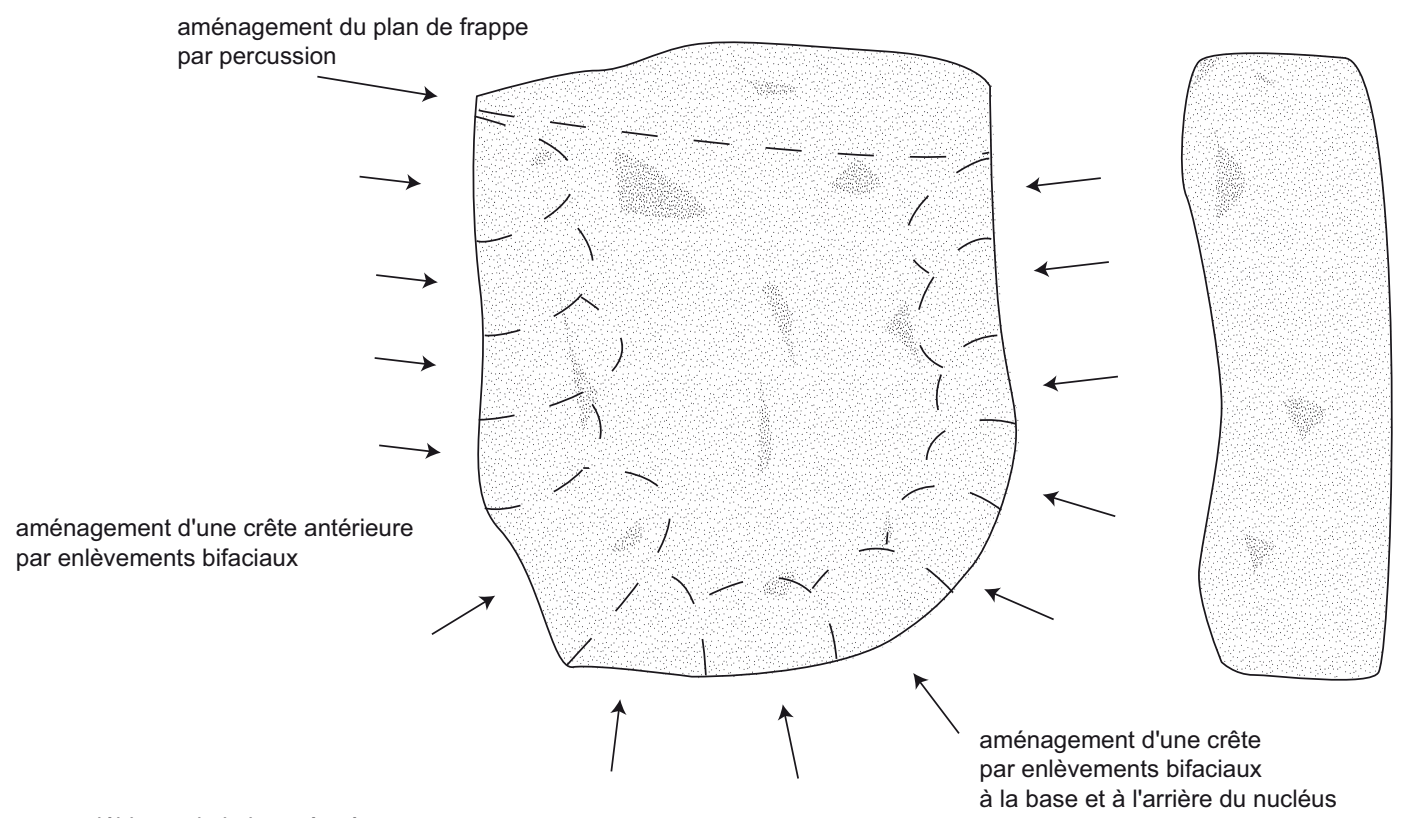

débitage de la lame à crête par percussion indirecte

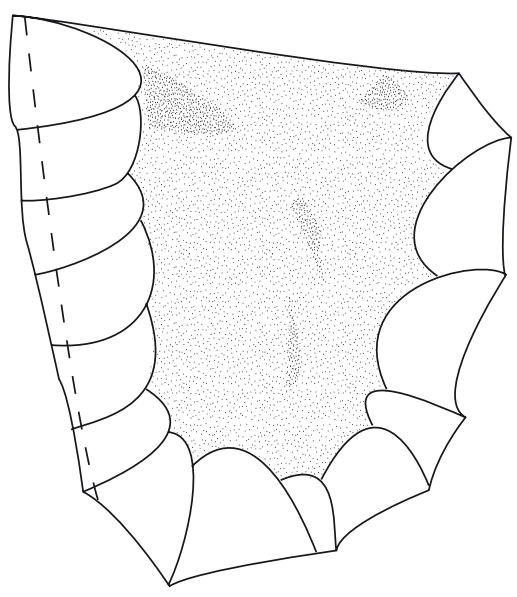

Fig. 10 - Proposition d'un schéma de mise en forme des nucléus et de la conduite du débitage sur les ateliers laminaires des environs de Collorgues (d'après propositions Briois, 2006; DAO: M. Remicourt).

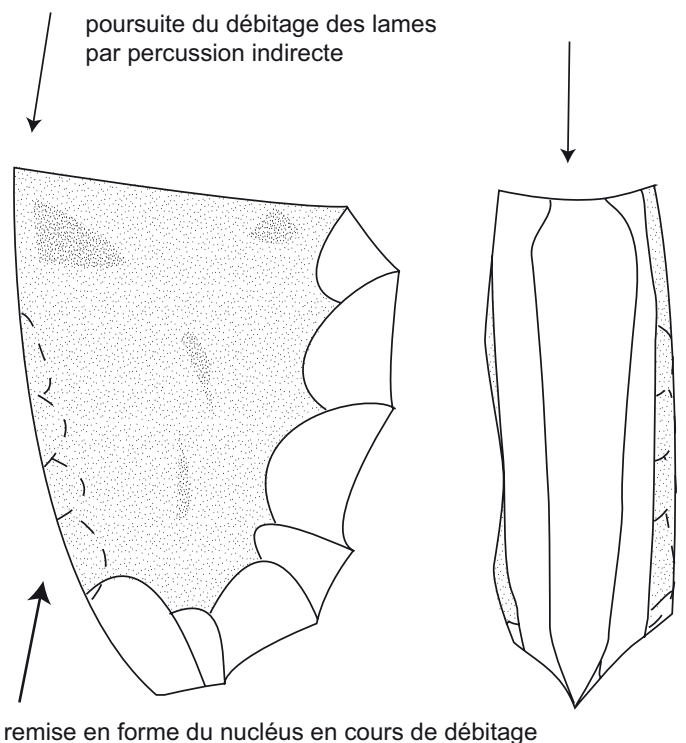

par des enlèvements en néocrête antéro-latérale

Théris à Méjannes-le-Clap, station de Beauvert à Connaux, stations de Mas de Vignoles IV et de Zac Esplanade Sud à Nîmes, etc.). L'emploi du silex en plaque du Ludien pour les gisements de la plaine du Bourdic n'est pas systématique et on note la présence importante du silex cénomanien des environs d'Uzès et d'un silex tertiaire, parfois rubané, dis- ponible dans des gîtes entre Alès et Nîmes. Sur ces stations, on identifie aussi un silex en plaquette du Ludien inférieur transformé en pièces foliacées ou en racloirs, mais ces pièces sont souvent rares dans les séries. Lorsque des lames attribuables au silex de Collorgues sont reconnues, ces pièces sont quasiment toujours transformées, au contraire de ce 


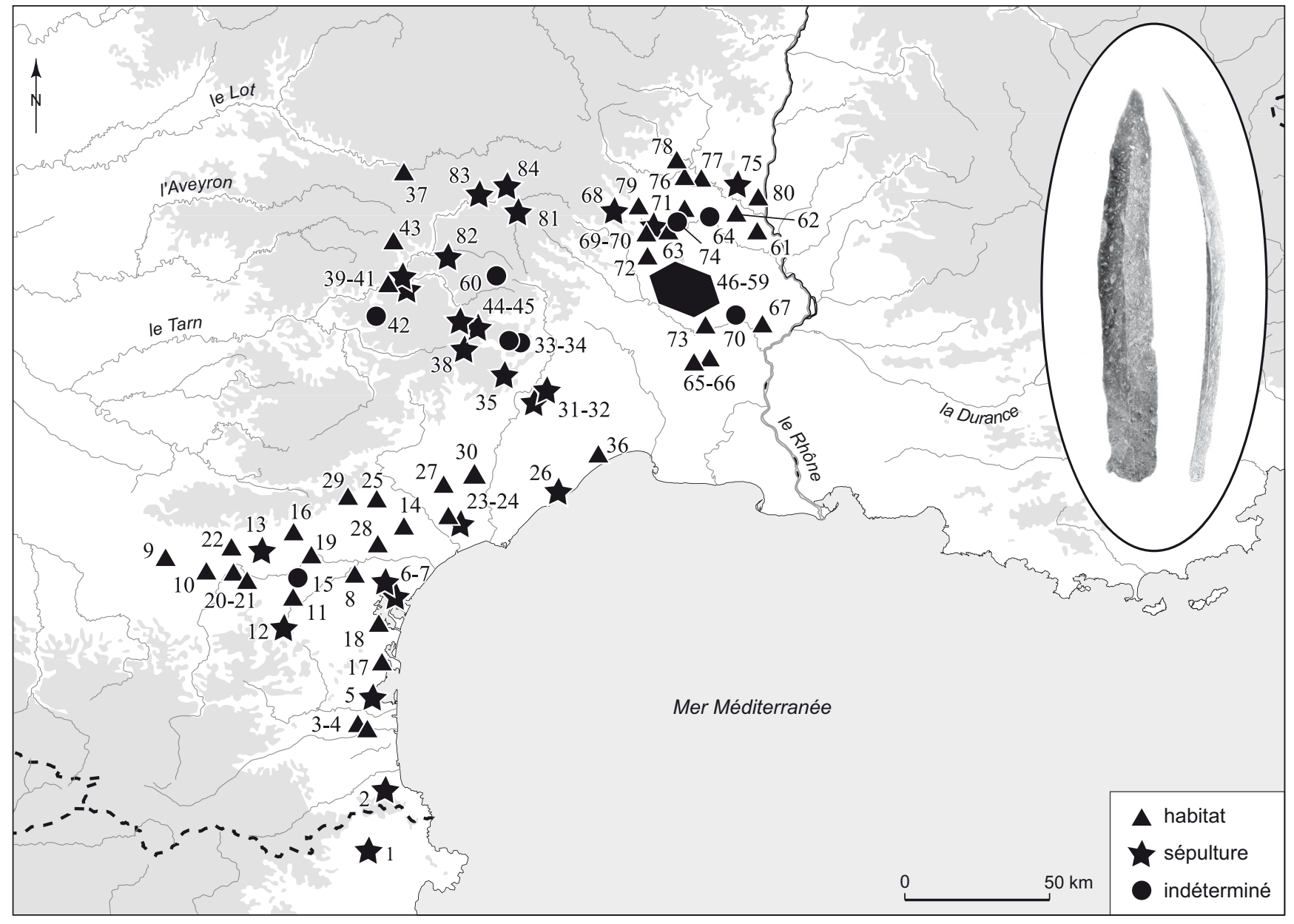

Catalogne :

1. Sépulture mégalithique de Fontanilles, Sant-Climent-Sescebes, Alt Empordá.

Pyrénées-Orientales :

2. Cova-de-la-Tortuga, Argelès-sur-Mer ; 3. Station de la Plage I, Caramany ; 4. Station des Coudoumines, Caramany ; 5 . Grotte du Portichol, Salses.

Aude :

6. Trou-du-Loup, Armissan ; 7. Grotte de Bringairet, Armissan ; 8. Gaussan, Bizanet ; 9. Buzerens, Bram ; 10. Saint-Antoine, Caux-et-Sauzens ; 11. Grotte de Sautadet, Lagrasse ; 12. Nécropole de la Clape, Laroque-de-Fa; 13. Dolmen de Saint-Eugène, Laure-Minervois ; 14. Le Moulin, Mailhac; 15. Grotte des Chambres-d'Alaric, Moux ; 16. Tinal d'Abrens, Peyriac-Minervois ; 17. Combe du Renard 2, Port-la-Nouvelle ; 18. Peyrou, Sigean ; 19. Castellas, Tourouzelle ; 20. Le Mourral, Trèbes ; 21. Béragne, Trèbes ; 22. Combes, Villeneuve-Minervois. Hérault :

23. Allée couverte de Cabrials, Béziers ; 24. Station de Courondelles, Béziers ; 25. Grotte de Camprafaud, Ferrières-Poussarou ; 26. Dolmen de la Coste, Frontignan ; 27. La Resclauze Gabian ; 28. Cazal de Rouch, Olonzac ; 29. Grotte Tournié, Pardailhan ; 30. Puech-Haut, Paulhan · 31. Dolmen de la Bergerie de Lavène, Puechabon ; 32 . Dolmen du Lac-Neuf, Puechabon ; 33. Aven III des Besses, Saint-Maurice-de-Navacelles ; 34. Grotte de Soulagets, Saint-Maurice-de-Navacelles ; 35. Dolmen de Saint-Pierre-de-la-Fage ; 36. Mort-des-Anes, Villeneuve-les-Maguelonne.

Aveyron :

37. Grotte de l'Ancise, Campagnac ; 38. Dolmen de la Couvertoirade ; 39. Grotte du Jas-del-Biau, Millau ; 40. Dolmen I de Saint-Martin-du-Larzac, Millau ; 41. Dolmen de Peyrolévado Millau ; 42. Grotte 3 de Sargel, Saint-Rome-de-Cernon ; 43. Grotte de la Médecine, Verrières.

Gard :

44. Dolmen de Campestre-et-Luc ; 45. Dolmen de Grailhe, Campestre-et-Luc ; 46. Sous-l'Arque, Baron ; 47. Grotte du Mas-de-l'Aveugle, Collorgues ; 48. Hypogée de Teste I, Collorgues : 49. Figaret Collorgues ; 50. Coste-Gajet, Collorgues ; 51. La Source, Foissac ; 52. Mas Nouguier, Saint-Maurice-de-Cazevieille ; 53 . Petit-Pin, Saint-Maurice-deCazevieille ; 54. Jaussaud-Est, Saint-Maurice-de-Cazevieille; 5 5. Montredon, Saint-Maurice-de-Cazevieielle ; 56. Pouget, Saint-Maurice-de-Cazevieille ; 5 7. Raymond, Saint-MauriceCazevieille ; 54. Jaussaud-Est, Saint-Maurice-de-Cazevieille ; 55. Montredon, Saint-Maurice-de-Cazevieielle ; 56. Pouget, Saint-Maurice-de-Cazevieille ; 57. Raymond, Saint-Maurice-
e-Cazevieille ; 58. L'Eolienne, Saint-Dézéry ; 59. Font-de-la-Goujat, Saint-Dézéry ; 60 . Grotte des Cabanes-du-Trévesel, Dourbies ; 61 . Chazalet, Carsan ; 62 . Station de Laval-SaintRoman ; 63. Grotte de Théris, Méjannes-le-Clap ; 64. Grotte du Travers, Montclus ; 65. Mas-de-Vignoles IV, Nîmes ; 66. Zac Esplanade Sud, Nîmes ; 67. Grotte du Taï, Remoulins ; 68. Dolmen de la Piste, Saint-Brès ; 69. Grotte I du Galinier, Saint-Jean-de-Maruéjols ; 70. Combe Raymonenque, Saint-Jean-de-Maruéjols ; 71. Grotte Saint-Joseph, Sainte-Anastasie ; 72. Terre Saud, Saint-Just-et-Vacquières ; 73. Montaïon, Sanilhac-et-Sagriès ; 74. Grotte des Fées, Tharaux.

Ardèche :

75. Dolmen II du Poza, Bidon ; 76. Serre-de-Boidon, Grospierres ; 77. Baume d'Oulen, Labastide-de-Virac ; 78. Grotte de Peyroche II, Saint-Alban-d'Auriolles ; 79. Grotte de Chazelles, Saint-André-de-Cruzières ; 80. Aven Meunier, Saint-Martin-d'Ardèche. Lozère :

81. Dolmen de Valbelle, Florac ; 82. Grotte Poujols, Hures-la-Parade ; 83. Dolmen de Combe-Lébrouse, Quézac ; 84. Tumulus de Dignas, Sainte-Enimie Gers (hors carte) :

85 : Station de Madone, Lamothe-Goas.

Fig. 11 - Carte de distribution du matériel laminaire en silex de Collorgues à la fin du Néolithique et au Chalcolithique dans le sud de la France et en Catalogne (inventaire Vaquer, Remicourt, 2008; DAO: M. Remicourt). 

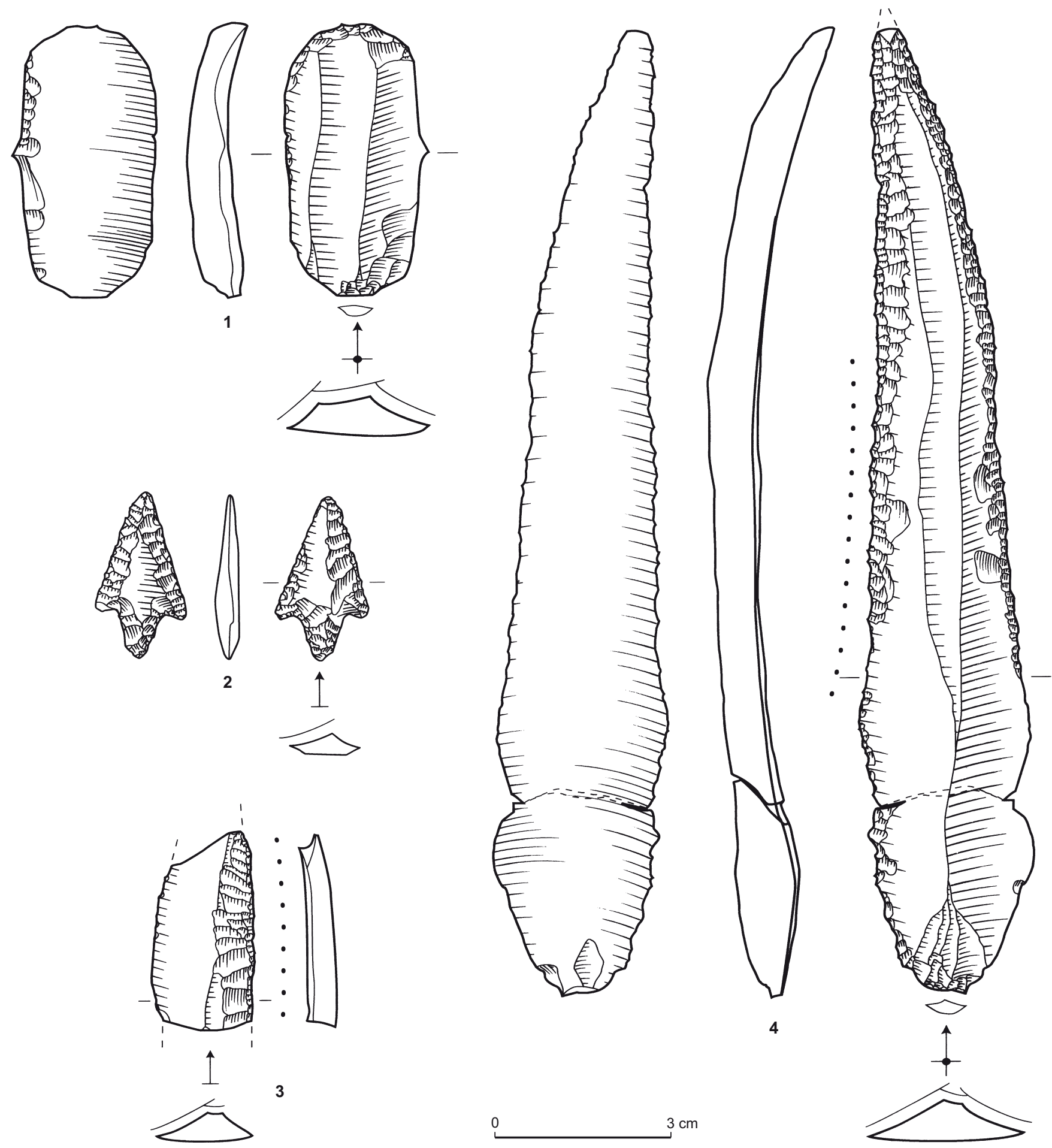

Fig. 12 - Exemples de lames découvertes sur les gisements archéologiques. 1: Station de Mas Nouguier, Saint-Maurice-de-Cazevieille (Gard), coll. Bordreuil, musée du Colombier, Alès; 2: Dolmen des Charbonniers, Rochegude (Gard), coll. CFRAN; 3 : Station de Coussergues, Béziers (Hérault), coll. Sendra; 4: Grotte-aven Poujols, Hures-la-Parade (Lozère), coll. Lacas (DAO: M. Remicourt). 


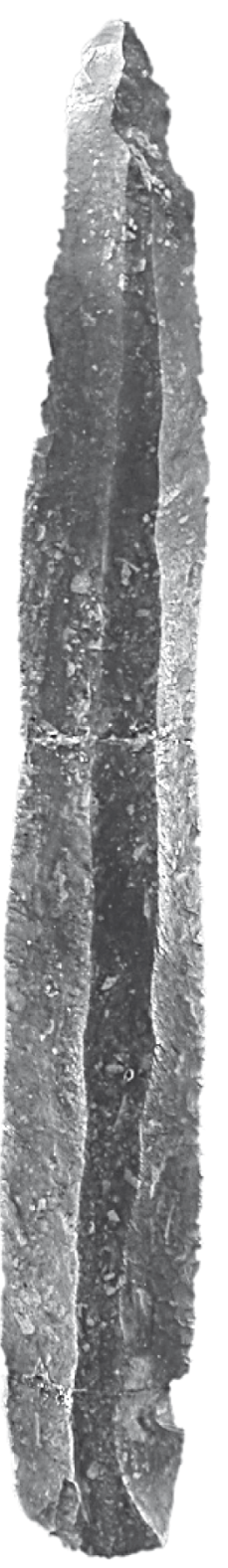

1

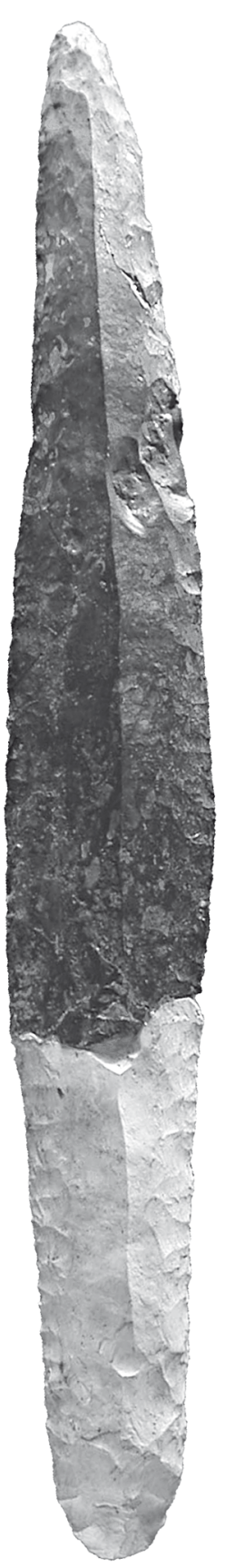

2
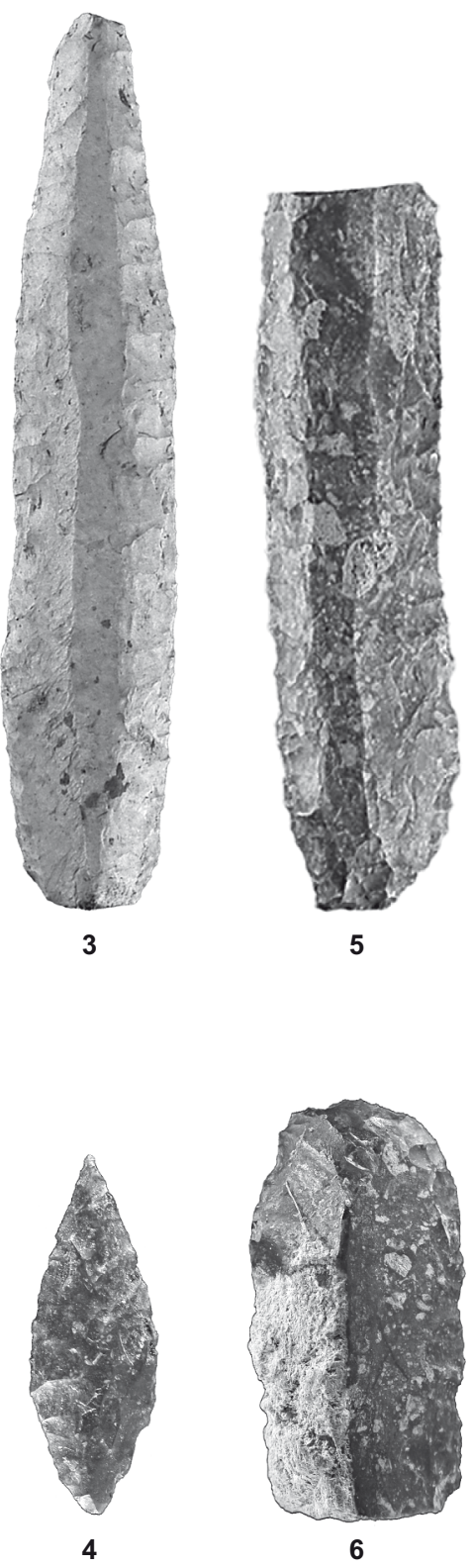

$3 \mathrm{~cm}$
Fig. 13 - Exemples de lames découvertes sur les gisements archéologiques. 1: Cova de la Tortuga, Argelès-sur-Mer (Pyrénées-Orientales), coll. musée de Céret; 2: Tumulus de Dignas, Sainte-Enimie (Lozère), coll. Fages, dépôt de fouilles de Banassac; 3: Dolmen de la Couvertoirade (Aveyron), coll. Cartailhac, Muséum d'histoire naturelle de Toulouse; 4: Grotte 3 de Sargel, Saint-Rome-de-Cernon (Aveyron), coll. Serres, musée municipal de Roquefort-sur-Soulzon ; 5 : Le Mourral, phase 2, Trèbes (Aude), coll. Vaquer, dépôt de fouilles de Carcassonne; 6: Grotte Chazelles, couche 6, Saint-André-de-Cruzières (Ardèche), coll. Nikitine, musée d'Orgnac (Clichés: 1 à 3 $H$. Vergély; 4 et 6 M. Remicourt; 5 J. Vaquer; DAO: M. Remicourt). que l'on peut observer sur les ateliers. La plupart de ces exemplaires sont à section trapézoïdale et de plein débitage, elles comportent souvent des retouches latérales, quelquesunes sont également façonnées en grattoir, en armature de flèche foliacée ou en poignard (fig. 12, n 1).
Dans la zone des ateliers et dans un rayon d'une dizaine de kilomètres, les séries archéologiques des habitats ne montrent pas une prédominance de pièces laminaires en silex de Collorgues. Le système de distribution de proche en proche ne semble donc pas être le principal vecteur de cette 
diffusion, car ces pièces seraient mieux représentées. De plus, on note la présence constante d'autres industries laminaires, que ce soit les lames provençales originaires d'AptForcalquier à la station du Clau-de-Montargues à SaintCésaire-de-Gauzignan (coll. Bordreuil), à l'aven sépulcral de Cromaton à La Bruguière ou sur des stations de SaintMaurice-de-Cazevieille, comme au Pouget 1 (Remicourt, 2007). Mais on trouve aussi des lames en silex bédoulien blond ou gris, originaires du Vaucluse, à l'aven sépulcral du Serre à Méjannes-le-Clap, au dolmen de la Bergeriede-Panissière à Anduze (ibid.), ou à la grotte de la Capelle à Tharaux (fouilles Alméras). Ce dernier site a également livré une lame en silex du Grand-Pressigny, comme d'autres gisements attribuables au groupe de Fontbouïsse, dont la station de Montredon à Castelnau-Valence (prospection Bordreuil) ou la grotte du Chemin de fer à Boucoiran (Coste et al., 1974).

Cette faible représentation des produits laminaires en silex de Collorgues à proximité des ateliers, de même que la présence de pièces laminaires allochtones, nous apportent quelques indices sur la production et la distribution des lames. La production de lames pourrait être le fait de petits groupes en partie autonomes des autres communautés contemporaines. Les différents indices qui ont été retrouvés sur les ateliers, tels les fragments de meules, les restes de faune, la céramique abondante, les vestiges de maisons, semblent indiquer que ces artisans étaient installés durablement et géraient leur économie de subsistance comme les autres groupes alentours. La diffusion des lames était ensuite soit contrôlée par les artisans producteurs eux-mêmes, soit prise en charge par un petit groupe de colporteurs s'occupant des échanges. Ce modèle serait proche pour certains points des propositions qui ont pu être émises quant à la gestion des productions laminaires pressigniennes dans le centre de la France (Pelegrin, 2002 et 2005).

\section{PLACE DES PRODUCTIONS LAMINAIRES DE COLLORGUES DANS LE SUD DE LA FRANGE}

À partir d'un territoire où les grandes lames sont en cours d'inventaire dans le cadre de deux PCR sur les régions PACA, Languedoc-Roussillon et Midi-Pyrénées, on observe une aire de diffusion préférentielle des productions laminaires en silex de Collorgues, qui correspond à peu près au pourtour méditerranéen à l'ouest du Rhône (fig. 11). Les lames en silex de Collorgues n'ont pour l'instant pas été identifiées à l'est du Rhône malgré les nombreux produits laminaires expertisés par certains membres du laboratoire du LAMPEA à Aix-en-Provence, S. Renault et C. Bressy. Même si l'importance des productions provençales, en silex bédoulien du Vaucluse et en silex oligocène de Forcalquier, a sans doute constitué un obstacle pour la diffusion des productions laminaires languedociennes, il serait étonnant que quelques exemplaires n'aient pas réussi à franchir le Rhône car de fortes influences languedociennes des groupes de Ferrières et de Fontbouïsse sont perceptibles sur ce territoire (Courtin, 1974; Cauliez, 2007).

Nos observations sur les produits laminaires dans le sud de l'Ardèche montrent une présence très forte des productions provençales; toutefois quelques exemplaires de lames en silex de Collorgues apparaissent dans les niveaux attribuables au groupe de Ferrières, comme à la Baume d'Oulen à Labastide-de-Virac. Mais ils sont nettement plus fréquents dans les niveaux attribuables au groupe de Fontbouïsse, comme à la grotte de Chazelles à Saint-Andréde-Cruzières. On les rencontre sur le territoire des Grands Causses, en Aveyron et en Lozère, qui semblent constituer la limite septentrionale de l'aire de diffusion préférentielle, car les quelques séries de lames du Cantal que nous avons pu examiner présentaient plutôt des exemplaires originaires du bassin oligocène de Mur-de-Barrez et d'Aurillac ou du Turonien supérieur du Grand-Pressigny. À l'ouest des Grands Causses, les séries archéologiques inventoriées dans les ségalas de l'Aveyron et le Lot n'ont pas non plus permis d'identifier d'importations provenant de Collorgues. Le Tarn n'ayant pour l'instant pas fait l'objet d'inventaires très poussés, il n'est pas possible de proposer un schéma pour la partie occidentale de la Montagne noire. Le bassin de l'Aude a livré de nombreux exemplaires, presque autant que les gisements aux alentours de Collorgues dans le Gard et l'Ardèche, mais, comme il s'agit de la zone où les inventaires de lames ont été menés en premier par J. Vaquer, il existe un biais de surreprésentation par rapports aux autres zones. Il semble que la limite occidentale de la diffusion préférentielle se situe environ au niveau de la ligne de partage des eaux, vers le seuil de Naurouze qui pourrait correspondre à peu près aux limites entre le Vérazien garonnais et le Vérazien méditerranéen (Vaquer, 1990). Au cœur de ce territoire, les gisements des garrigues et plaines languedociennes présentent de façon récurrente des pièces laminaires en silex de Collorgues. On retrouve quelques exemplaires dans le sud-est des Pyrénées-Orientales et dans le nord de la Catalogne qui constituent pour le moment les pièces les plus méridionales. Hors de cette aire de diffusion préférentielle, on connaît une armature de flèche foliacée sur lame en silex de Collorgues à la station de Madone, à 
Tabl. I - Dates radiocarbones de quelques gisements avec du matériel laminaire en silex de Collorgues au Néolithique final et au Chalcolithique dans le sud de la France (DAO: M. Remicourt).

\begin{tabular}{|c|c|c|c|c|}
\hline Gisement & Date ${ }^{14} \mathrm{C}$ & $\begin{array}{l}\text { Calib. } 1 \delta \\
\text { av. J.-C. }\end{array}$ & $\begin{array}{l}\text { Calib. } 2 \delta \\
\text { av. J.-C. }\end{array}$ & Groupe \\
\hline Mas de Vignoles IV, Nîmes, Gard & Erl $11788: 4675 \pm 88 \mathrm{BP}$ & $3630-3360$ & $3650-3100$ & Pré-Ferrières \\
\hline Grotte Tournié C22, Pardailhan, Hérault & MC $1282: 4650 \pm 100 \mathrm{BP}$ & $3640-3190$ & $3650-3050$ & Saint-Ponien \\
\hline Puech-Haut phase 1, Paulhan, Hérault & Ly 1868(Poz-1019) : $4590 \pm 40 \mathrm{BP}$ & $3500-3130$ & $3510-3100$ & Néolitique final \\
\hline Tumulus de Dignas, Sainte-Enimie, Lozère & MC $569: 4530 \pm 90 \mathrm{BP}$ & $3370-3090$ & $3550-2900$ & Treilles, phase ancienne \\
\hline Tumulus de Dignas, Sainte-Enimie, Lozère & Gif $5876: 4460 \pm 70 \mathrm{BP}$ & $3340-3020$ & $3350-2920$ & Treilles, phase ancienne \\
\hline Baume d'Oulen C1, Labastide-de-Virac, Ardèche & MC $2032: 4490 \pm 100 \mathrm{BP}$ & $3350-3020$ & $3500-2900$ & Ferrières \\
\hline Le Mourral phase 1, Trèbes, Aude & Ly $7468: 4485 \pm 75$ BP & $3350-3090$ & $3370-2920$ & Vérazien, phase ancienne \\
\hline Le Mourral phase 1, Trèbes, Aude & Ly $8250: 4480 \pm 50 \mathrm{BP}$ & $3340-3090$ & $3360-3010$ & Vérazien, phase ancienne \\
\hline Le Mourral phase 2, Trèbes, Aude & Ly $7467: 4455 \pm 45 \mathrm{BP}$ & $3330-3020$ & $3340-2930$ & Vérazien, phase ancienne \\
\hline Camprafaud C7, Ferrières-Poussarou, Hérault & Gif $3076: 4380 \pm 110 \mathrm{BP}$ & $3330-2890$ & $3400-2650$ & Vérazien, phase moyenne \\
\hline Grotte Tournié C20, Pardailhan, Hérault & MC $905: 4300 \pm 100 \mathrm{BP}$ & $3100-2700$ & $3350-2600$ & Vérazien, phase moyenne \\
\hline Grotte Tournié C14, Pardailhan, Hérault & MC $1133: 4130 \pm 80 \mathrm{BP}$ & $2870-2580$ & $2900-2490$ & Vérazien, phase finale \\
\hline Grotte de Théris A, Méjannes-le-Clap, Gard & Gif $7297: 3900 \pm 80 \mathrm{BP}$ & $3480-2210$ & $2580-2130$ & Fontbouïsse \\
\hline
\end{tabular}

Lamothe-Goas dans le Gers, à un peu plus de $300 \mathrm{~km}$ à vol d'oiseau de la zone productrice.

À l'ouest du Rhône, l'aire de diffusion préférentielle des lames en silex de Collorgues correspond à un réseau régional d'environ $200 \mathrm{~km}$ de diamètre, dont les limites septentrionales sont marquées par le domaine caussenard, les limites occidentales par la ligne de partage des eaux au-delà du bassin de l'Aude et la limite méridionale par les Pyrénées. Ce réseau de distribution de lames est «transculturel» aux diverses phases de son développement puisqu'il concerne d'abord les groupes de Ferrières, de Saint-Pons et des Treilles ancien, puis de Fontbouisse, de Véraza et des Treilles récent. Le territoire cerné à partir de cette diffusion des lames comporte sans doute plus d'unité et d'affinités culturelles que la subdivision en de multiples groupes définis à partir de la céramique ne le propose. Ce réseau de distribution n'atteint toutefois pas le rayonnement important des productions du Grand-Pressigny venues concurrencer les productions locales jusque dans les zones d'ateliers à Collorgues. Il est également plus limité que celui des ateliers de Forcalquier dont les productions ont été diffusées jusqu'au bassin du Pô, à la Suisse occidentale, au Levant espagnol et au Pays basque. Il a un rayonnement moindre que celui des ateliers du Vaucluse dont les productions se retrouvent des Alpes au sud de la Catalogne. Il semble en revanche plus étendu que celui des lames en silex de Mur-de-Barrez (Aveyron), tel que nous le percevons actuellement. Les différents critères, comme la matière première, la longueur, la régularité, la courbure des pièces, ont pu être des qualités qui l'emportaient aux yeux des populations préhistoriques sur la distance par rapport aux sources ou sur les diverses modalités de distribution telles qu'elles ont été envisagées (Renfrew, 1984).

\section{LE MATÉRIEL LAMINAIRE EXPORTÉ}

\section{CHRONOLOGIE RELATIVE ET ABSOLUE DES PIÈCES LAMINAIRES SUR LES GISEMENTS RÉCEPTEURS}

Nous ne disposons pas de données chronologiques précises dans les zones de production, que ce soit les galeries de mines d'extraction de silex ou les ateliers laminaires. Pour essayer de dégager des jalons temporels, nous devons avoir recours aux gisements récepteurs de pièces laminaires (tabl. I). Les plus anciens exemplaires de lames en silex de Collorgues sont attribuables au Néolithique final (environ 3500-3200 av. J.-C.) dans le Languedoc. Ils correspondent sans doute à la fin de cette période. Il s'agit d'un exemplaire dans les niveaux saint-poniens de la grotte Tournié, à Pardailhan dans l'Hérault (Vaquer et al., 2006a) et d'un autre dans les niveaux pré-Ferrières du Mas de Vignoles IV à Nîmes dans le Gard (Jallot, 2004; Remicourt, 2006) pour lesquels nous disposons d'une date radiocarbone sur un os de faune; Erl-11788: $4675 \pm 88$ BP, soit 3650-3100 av. J.-C. Ces pièces sont très rares dans les séries de cette période, où les productions laminaires provençales dominent. L'une des pièces est retouchée latéralement, la seconde transformée en grattoir.

Au Chalcolithique ancien (environ 3200-2800 av. J.-C.), la production de lames en silex de Collorgues semble être 
à son acmé. Dans certaines séries archéologiques riches en lames, elles sont désormais parfois très bien représentées. Au Puech-Haut à Paulhan dans l'Hérault, treize exemplaires appartiennent à la phase 1, contemporaine du groupe de Ferrières (Ly 1868 (Poz-1019) : 4590ะ40 BP soit 3510-3100 av. J.-C.). Les productions provençales (Forcalquier et Ventoux) sont ici minoritaires avec onze pièces (Perrin, Briois, 2005). Ce cas de figure se répète dans l'Aude avec les séries des gisements attribuables au Vérazien ancien à la station de Saint-Antoine à Caux-et-Sauzens et à l'enceinte du Mourral à Trèbes (fig. 13, $\mathrm{n}^{\circ} 5$; Vaquer et al., 2006c), où les lames en silex de Collorgues représentent $30 \%$ (19 lames) du matériel laminaire sur le premier gisement et $40 \%$ (11 lames) sur le second face aux lames en matières premières provençales. Les datations radiocarbone du Mourral placent cette épisode entre 3300 et 2900 av. J.-C.

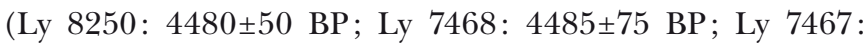
$4455 \pm 45$ BP). En Ardèche, les lames en silex de Collorgues absentes dans les assemblages plus anciens apparaissent dans les niveaux attribuables au groupe de Ferrières, comme dans la couche 1 de la Baume d'Oulen à Labastide-de-Virac (Roudil, 1984). Dans le Gard, on peut citer un exemplaire à la station de Montaïon à Sanilhac-et-Sagriès (Gutherz, Jallot, 1987) et un sur le gisement de Zac Esplanade Sud, à Nîmes (Hervé et al., 1999; Remicourt, Bressy, 2007). Sur les Grands Causses, on constate la présence de trois lames en silex de Collorgues au tumulus de Dignas, à Sainte-Enimie en Lozère (Fages, 1983) ; ce monument est daté de la phase

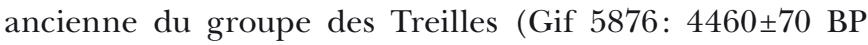
soit 3350-2920 av. J.-C.). Deux exemplaires ont également été recensés dans les niveaux contemporains de la grotte de la Médecine, à Verrières en Aveyron (Soutou, 1967). La plupart de ces pièces sont retouchées latéralement ou transformées en grattoirs. Toutefois, il existe quelques poignards foliacés, comme l'une des pièces brûlées du tumulus de Dignas (fig. 13, n²).

Dans les niveaux attribuables au Chalcolithique moyen (environ 2800-2400 av.J.-C.), les lames en silex de Collorgues sont encore bien représentées dans les séries archéologiques, alors que le taux général des supports laminaires est en baisse. Cet état de fait a été interprété par certains comme le résultat d'une concurrence plus grande avec les pièces sur silex en plaquette (Vaquer, Vergély, 2006) et au début de la prépondérance des pièces métalliques sur les pièces lithiques dans la région (Vaquer et al., 2006b). De nombreux gisements attribuables au groupe de Fontbouisse ont livré des lames en silex de Collorgues. Dans le Gard, on peut citer le Mas de Vignoles IV (Jallot, 2004) avec cinq fragments de lames, deux pièces dans la stratigraphie fontbuxienne de la grotte de Théris, à Méjannes-le-Clap (Forestier, 1990), et le poignard de la grotte I du Galinier, à Saint-Jean-de-Maruéjols (Bordreuil, 1992). En Ardèche, deux lames sont présentes dans les niveaux fontbuxiens de la grotte de Peyroche II, à Saint-Alban-d'Auriolles (Roudil, Saumade, 1985), une sur la station du Serre-de-Boidon, à Grospierres (Gros, 1972) et quatre à la grotte de Chazelles à Saint-André-de-Cruzières (fig. 13, n 6; Combier, 1980). Pour la phase finale du Vérazien, on trouve encore quelques pièces sur les gisements orientaux, proches de l'aire géographique du groupe de Fontbouïsse, comme dans la couche 14 de la grotte Tournié à Pardailhan, Hérault (Vaquer et al., 2006a), qui est datée par le ${ }^{14} \mathrm{C}$ (MC 1133: 4130 \pm 80 BP soit 2900-2490 av. J.-C.). On retrouve les mêmes transformations de pièces qu'aux périodes antérieures, avec des retouches latérales, des grattoirs, des poignards foliacés comme à la grotte I du Galinier et quelques armatures de flèches foliacées sur lames, comme la pièce de la station de Combe Raymonenque, à Saint-Jean-de-Maruéjols dans le Gard (coll. CFRAN).

Pour les Grands Causses, le Roussillon et une grande partie du Languedoc occidental, nous ne disposons pas pour le moment de support laminaire originaire de Collorgues dans des niveaux bien calés attribuables aux dernières phases du groupe des Treilles ou au Vérazien, hormis dans son extension orientale. Cette absence est peut-être liée à la rareté des gisements dotés d'une chronologie fine pour les Grands Causses, la plupart des sites étudiés correspondant à des sépultures collectives de longue durée, fouillées anciennement. Toutefois, elle paraît plus significative sur une grande partie du Languedoc occidental qui a livré de nombreux gisements attribuables à la fin du Vérazien, comme la phase 2 de l'enceinte du Roc-d'en-Gabit, à Carcassonne (Vaquer, 1999). Il est probable que l'aire de diffusion préférentielle des lames en silex de Collorgues ait connu une rétraction sur le territoire du Languedoc oriental au Chalcolithique et n'ait dès lors plus joué qu'un rôle dans l'approvisionnement local des populations du groupe de Fontbouïsse et de leurs plus proches voisins. Cette hypothèse reste à valider par les enquêtes projetées sur les grandes lames dans les séries les plus représentatives.

Les différentes études menées sur les séries lithiques attribuables au complexe campaniforme en Languedoc oriental et dans les régions adjacentes (Furestier, 2007), de même que les séries laminaires inventoriées dans le cadre des PCR, semblent plaider pour la fin de l'exploitation et de 
la production de lames en silex de Collorgues avant l'arrivée des premiers porteurs de gobelets.

\section{LES EXPORTATIONS DE LAMES EN SILEX DE COLLORGUES : QUELQUES GARACTÈRES TECHNOLOGIQUES}

La lecture technologique des lames en silex de Collorgues exportées offre, comme on s'en doute, de nombreux parallèles avec les productions des ateliers de débitage de lames. On retrouve les différents stigmates qui traduisent une production par percussion indirecte, avec des lèvres saillantes, des bulbes peu marqués à marqués, des nervures généralement sinueuses, des faces inférieures ondulées, des produits à profil arqué. Cette courbure et les extrémités distales généralement aigues sont également liées aux formes «en mitre» des nucléus connus sur les ateliers (Briois, 2006). Toutefois, des différences ressortent entre le matériel laminaire exporté et celui découvert en contexte d'atelier. En effet, si l'on prend en compte les sections des lames exportées, on constate une surreprésentation des produits trapézoïdaux de plein débitage qui représentent un peu plus de $50 \%$ du corpus, alors qu'elles ne représentent que $10 \%$ à $17 \%$ des produits sur les sites d'atelier. Cette sélection réduit le taux des lames à bord cortical ou sous-crête à 21,75\% du corpus des lames exportées, pour 66,6 \% à Paléo-Figaret et 76,05\% à Moulin de Gattigues. Les produits exportés sont aussi plus larges et moins épais que les pièces découvertes en contexte d'atelier, ce qui s'explique en partie par la prépondérance des lames à section trapézoïdale sur les lames à section triangulaire (fig. 14). Ces différents critères traduisent le tri opéré dans la production qui privilégiait pour l'exportation les lames à section trapézoïdale les plus larges et les moins épaisses.

Il n'existe pas encore d'études tracéologiques sur les pièces laminaires en silex de Collorgues exportées, il est donc difficile de proposer des schémas sur leur utilisation et leur abandon à divers stades, qu'elles soient laissées brutes ou plus ou moins retouchées. Une partie des lames brutes sont-elles restées brutes car elles étaient déjà assez étroites? Ou bien ces pièces, qui représentent une minorité, ont-elles simplement été laissées de côté après un premier stade d'utilisation sans faire l'objet d'un ravivage et/ou d'un remploi ultérieur par l'adjonction de retouches? La comparaison des diagrammes des largeurs en fonction des épaisseurs de ces deux types semble favoriser la seconde hypothèse (fig. 14). En effet, les lames brutes ou les lames retouchées, dont la largeur donnée correspond à la largeur mesurée de «l'outil», ne semblent pas être regroupées autour d'une mesure bien précise. Les lames transformées, surtout retouchées latéralement, mesurent principalement entre $1,5 \mathrm{~cm}$ et $2,5 \mathrm{~cm}$ de largeur au moment de leur abandon, avec un degré de ravivage des flancs plus ou moins poussé. Les critères morphométriques ne semblent donc pas être les seuls points qui entrent en jeu pour les divers stades d'utilisation, de réutilisation et d'abandon des pièces.

\section{LES EXPORTATIONS DE LAMES EN SILEX DE COLLORGUES : TRANSFORMATIONS ET STATUT}

L'étude du matériel laminaire retrouvé sur les gisements récepteurs semble montrer que les pièces en silex de Collorgues destinées à l'exportation ont été laissées brutes, ou peu retouchées. Les lames brutes entières recensées à ce jour se limitent à deux exemplaires et ont été découvertes dans des ensembles sépulcraux, à la Cova de la Tortuga, à Argelès-sur-Mer dans les Pyrénées-Orientales (fig. 13, $\mathrm{n}^{\circ} 1$; Baills, 1972) et à l'allée couverte de Cabrials à Béziers dans l'Hérault (fouilles Y. Tchérémissinoff 2007). Il existe également quelques pièces quasi entières faiblement retouchées comme le poignard à base brute de la grotte Poujols à Hures-la-Parade en Lozère (fig. 12, no 4). Malgré cet effectif restreint, l'hypothèse de l'exportation de lames brutes semble plausible; en effet, contrairement à ce que l'on connaît pour certains ateliers de production laminaire comme au Grand-Pressigny en Touraine ou dans quelques cas à Forcalquier en Provence, il ne semble pas exister à Collorgues une production et une exportation de poignards préformés stéréotypés (Sauzade, 1975; Mallet, 1992; Vaquer et al., 2006b). Ce constat d'exportation de lames brutes ou faiblement retouchées semble être un facteur récurrent dans le sud de la France si l'on examine la majeure partie des productions provençales (Renault, 1998 et 2006).

Ces pièces qui arrivaient brutes semblent être intégrées dans le processus de l'économie domestique en parallèle avec la batterie d'outillage disponible à partir des éclats. Ainsi, sur les 118 pièces recensées pour le moment, $56 \%$ portent des retouches latérales ou bilatérales semi-abruptes à abruptes, $14 \%$ correspondent à des grattoirs dont la moitié sont des pièces à retouches latérales transformées sans doute après fracture, $13 \%$ ont les flancs laissés bruts, $12 \%$ correspondent typologiquement à des poignards, $5 \%$ à des armatures de flèches foliacées et $1 \%$ à des perçoirs (fig. 12-13).

Contrairement à certaines pièces laminaires en silex du Grand-Pressigny ou en silex de Forcalquier sur les Grands 


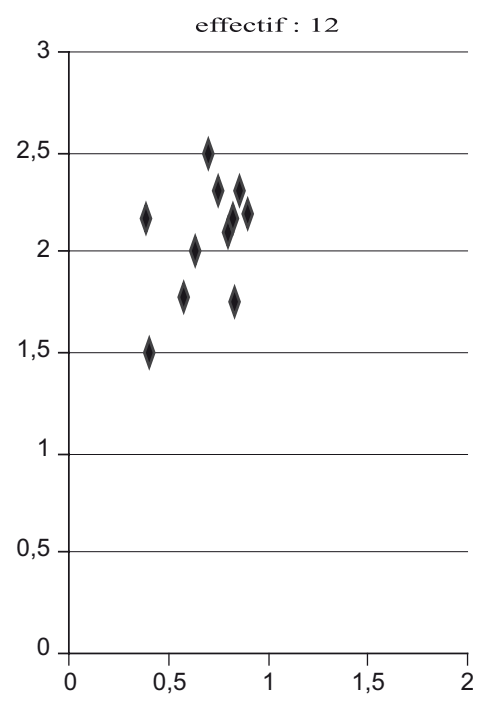

moyenne lame brute

largeur : 2,06 cm écart-type : 0,29 épaisseur : 0,69 $\mathrm{cm}$ écart-type : 0,17 moyenne lame retouchée

largeur : 1,95 cm écart-type : 0,37 épaisseur : 0,61 cm écart-type : 0,17

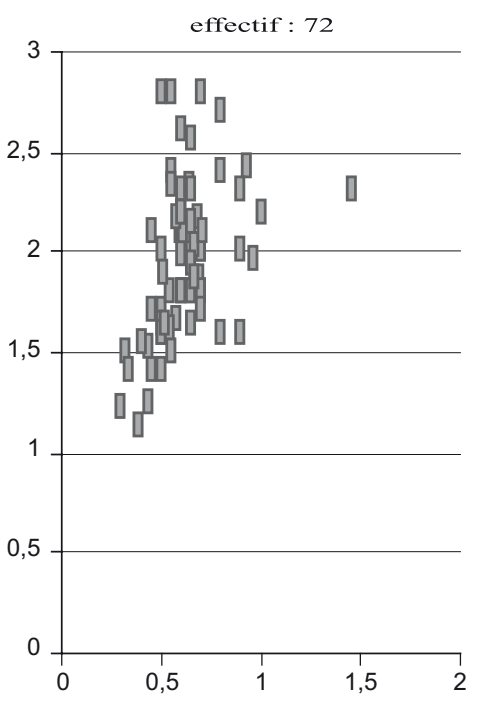

moyenne générale lame

largeur : $1,97 \mathrm{~cm}$ écart-type : 0,36 épaisseur : $0,62 \mathrm{~cm}$ écart-type : 0,17

\begin{tabular}{|c|c|c|c|c|c|c|c|c|c|}
\hline lames & $\mathrm{A} 1$ & $\mathrm{~A} 2$ & $\mathrm{~B} 1$ & $\mathrm{~B} 2$ & $\mathrm{C} 1$ & $\mathrm{C} 2$ & Cind & $\mathrm{D}$ & total \\
\hline entière & & & & & & 1 & & & 1 \\
\hline proximale & 2 & 2 & 3 & 1 & 3 & 8 & 4 & 2 & 25 \\
\hline mésiale & 7 & 3 & 12 & & 5 & 6 & 8 & 1 & 43 \\
\hline distale & 2 & 1 & 2 & & 2 & 2 & 2 & 1 & 12 \\
\hline total & 11 & 6 & 17 & 1 & 10 & 17 & 14 & 4 & 80 \\
\hline
\end{tabular}

Produits laminaires exportés :

- lames à bord cortical ou sous-crête : $21,75 \%$

- lames de plein débitage : 73,75\%

Produits laminaires sur les ateliers

- lames à bord cortical ou sous-crête Paléo-Figaret : 66,66 \%

- lames à bord cortical ou sous-crête Moulin de Gattigues : 76,05\%

- lames de plein débitage Paléo-Figaret : 31,25\%

- lames de plein débitage Moulin de Gattigues : 19,71\%

Fig. 14 - Morphométrie et classement technologique des lames exportées découvertes dans le sud de la France à la fin du Néolithique (DAO: M. Remicourt).

Causses et les garrigues languedociennes, les lames en silex de Collorgues ne font jamais l'objet d'apprêts particuliers en poignards, avec polissage d'une face ou des deux et adjonction d'échancrures pour l'emmanchement. Ce constat s'applique également aux pièces laminaires en silex bédoulien gris ou blond du Ventoux ou en silex oligocène de Mur-deBarrez. Le degré de réutilisation des fragments de lames en silex de Collorgues semble nettement moindre que celui des pièces en silex de Forcalquier. En effet, on rencontre rarement, dans les séries laminaires, des pièces en silex de Collorgues presque aussi épaisses que larges à retouches abruptes traduisant des ravivages latéraux répétés, comme c'est le cas pour les productions laminaires de la vallée du Largue. Ces différences de traitement pourraient être la traduction d'une hiérarchie de valeur qui a existé entre les matières premières dans la pensée et le comportement des populations réceptrices des produits laminaires. Dans cette hypothèse, les produits laminaires en silex de Collorgues ne seraient pas la matière première la plus prisée dans le sud de la France à la fin du Néolithique, cédant cette primauté au silex de Forcalquier dans les premiers temps, rejoint par le silex du Grand-Pressigny à la fin de la période. Si l'on prend toujours en compte ce mode de transformation différentielle dans l'aire géographique traitée, les productions en silex de Collorgues ont sans doute un statut plus proche des produits en silex bédoulien du Ventoux et en silex oligocène du bassin de Mur-de-Barrez et d'Aurillac (Aveyron et Cantal). Toutefois, ces produits laminaires 
avaient sans doute une valeur plus grande que les outillages sur éclats.

Même si les lames avaient une fonction utilitaire chez les populations réceptrices, comme en témoignent leur transformation et leur utilisation plus durable et diversifiée que les pièces sur éclat, leur statut devait toutefois être plus complexe. En effet, l'existence de lames déposées brutes dans les sépultures, ou la transformation en poignards de certaines d'entre elles, pose le problème du rôle de ces pièces dans les sociétés de la fin du Néolithique. La rareté des lames brutes en silex de Collorgues retrouvées à ce jour ne plaide pas pour un statut particulier de la lame entière, tel qu'on peut le rencontrer dans l'Énéolithique bulgare, comme à Varna (Manolakakis, 2006). S'il existe un statut particulier, il semble plutôt être en lien avec la matière première. À la fin du Néolithique dans le sud de la France, les lames en silex de Collorgues semblent être destinées à être fragmentées et à devenir des composantes d'outils. Elles ne sont qu'exceptionnellement transformées en poignards, comme la plupart des lames, à l'exception des produits en silex du Grand-Pressigny.

Le concept de «monnaie-marchandise», exploré dans toute sa complexité chez les Baruya de Nouvelle-Guinée avec les lingots de sel produits par des spécialistes pour être en partie échangés et dont la destination est à la fois ostentatoire, symbolique et utilitaire, car ils seront un jour consommés (Godelier, 1969), pourrait peut-être s'appliquer au cuivre ou aux lames en silex dans la société de la fin du Néolithique. Pour de nombreuses populations, une marchandise n'a de valeur d'échange que parce qu'elle a une valeur d'usage, qu'elle est consommable. Le prix de cette marchandise peut être d'autant plus grand qu'elle est physiquement rare. Toutefois, comme les objets sacrés, les objets précieux sont investis d'une valeur imaginaire qui n'a rien à voir avec le travail nécessaire pour les découvrir et les fabriquer, ni avec leur rareté relative (Godelier, 2007). K. Polanyi, qui a développé le concept et l'historique du caractère universel de la monnaie dans toutes les sociétés, propose que, pour une partie des sociétés antéhistoriques, il n'existe pas d'objet monétaire en soi et que tout objet peut fonctionner comme monnaie, celle-ci étant à usage limité et non universel, l'objet monétaire se distinguant dès lors de l'appareil comptable tel qu'on le connaît aujourd'hui (Polanyi, 1968). Ces artéfacts, comme toute monnaie, représentent un moyen de communication, à l'égal de la parole ou de la parure (Servet, 1993).

Dans le cas des grandes lames en silex à la fin du Néolithique dans l'aire de diffusion préférentielle qui a pu être définie en partie, un statut recouvrant ce triptyque de l'ostentatoire, du symbolique et de l'utilitaire pourrait s'appliquer. En effet, ces artéfacts, produits sur des lieux précis par des spécialistes et destinés à l'exportation grâce à l'existence de liens continus qui permettent l'approvisionnement, n’ont pas une utilité spécifique dans l'économie de subsistance, même si elles y participent. Les productions d'éclats permettaient d'obtenir des composants d'outils susceptibles de fournir aux populations les objets nécessaires à leur quotidien. Même si elles jouent un rôle dans l'économie de production journalière, elles représentent un superflu qui, associé à leur rareté, leur permettrait d'acquérir ce statut ostentatoire et symbolique, en participant tout à la fois à un système d'échanges complexe dans lequel elles ont une valeur économique, voire marchande.

Hors de l'aire de diffusion préférentielle, ce statut évoluerait encore vers d'autres systèmes, comme dans le cas des grandes lames de silex découvertes en Catalogne où les exemplaires entiers, souvent laissés bruts, semblent être plus fréquents que dans le sud de la France pour les produits originaires des ateliers provençaux, voire languedociens (Clop et al., 2006). Plusieurs facteurs pourraient être impliqués dans ce comportement différentiel, comme l'absence de réseaux et de liens réguliers permettant de s'en procurer facilement, mais également l'éloignement des sources qui accentuerait leur valeur. Définir le statut d'un objet, qu'il soit archéologique ou non, est cependant périlleux et aléatoire, car il peut être tour à tour acheté et vendu comme une marchandise, circuler comme objet de don et contre-don, et être finalement enfoui comme un trésor (Panoff, 1980). Son statut pourra donc évoluer en fonction du contexte de découverte, qu'il soit funéraire, en habitat, plus ou moins éloigné des sources, mais également selon le type de transformation ou l'absence de celle-ci sur les pièces.

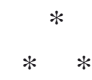

À l'issue de ce tour d'horizon des diverses connaissances ou propositions qui ont trait aux produits laminaires en silex de Collorgues, quelques pistes ont pu être soulignées. Rappelons que, contrairement aux productions laminaires pressigniennes ou provençales, peu de travaux ont été menés sur les lames en silex de Collorgues et que, par conséquent, tous les aspects ne peuvent pas être perçus. Il faudrait fouiller des aires d'activités d'extraction et de taille pour préciser les modalités et la complexité des processus, sociaux, artisanaux ou économiques, qui sont entrés en jeu 
pour permettre la production, l'exportation et la réception des lames. On peut toutefois désormais affirmer que la production de lames dans les environs de Collorgues n'est pas un phénomène marginal et anecdotique comme certains avaient pu le proposer par le passé. En effet, les différents indices récoltés indiquent la mise en place d'une infrastructure minière conséquente qui va de pair avec une connaissance des ressources siliceuses et une maîtrise de l'art des mines par une partie de la population. Les blocs extraits qui étaient acheminés vers des ateliers étaient ensuite traités par des artisans maîtrisant l'art de la taille laminaire, et non par n'importe quel quidam. De fait, les séries lithiques découvertes dans les ateliers indiquent une normalisation de la taille, que ce soit les nucléus «en mitre» à forme stéréotypée, ou encore une série de gestes conventionnels comme la préparation des corniches par l'abrasion et enlèvements microlaminaires, ou encore l'utilisation de la percussion indirecte pour détacher les pièces. Une organisation et une gestion de l'exportation sont également notables, car l'on constate un tri et un choix des artéfacts destinés à être échangés à plus ou moins longue distance. Cette production est loin d'être un épiphénomène car, à la lecture des séries archéologiques, elle semble avoir duré plusieurs centaines d'années sans interruption sensible. La production laminaire en silex de Collorgues appartient donc à ces phénomènes importants de l'économie des sociétés néolithiques et chalcolithiques tant à une échelle locale que régionale, dans une aire de diffusion préférentielle qui va du Rhône aux Pyrénées. Car, dans cette économie primitive, les productions laminaires, en silex de Collorgues ou autre, sont impliquées dans les activités de subsistance tout en participant à d'autres activités moins perceptibles qui pourraient être en relation avec l'exercice des fonctions et des statuts les plus valorisés dans la société. 


\section{BIBLIOGRAPHIE}

\begin{tabular}{ll}
\multicolumn{1}{c}{ ABRÉVIATIONS } \\
ADAL & Association pour le développement de l'archéologie en Languedoc-Rousillon. \\
AEP & Archives d'écologie préhistorique. \\
APDCA & Association pour la promotion et la diffusion des connaissances archéologiques. \\
BAR & British Archaeological Reports. \\
BRGM & Bureau de recherche géologique et minière. \\
BSPF & Bulletin de la Société préhistorique française. \\
CFRAN & Centre de formation et de recherches archéologiques noiséens. \\
CTHS & Comité des travaux historiques et scientifiques. \\
DFS & Document final de synthèse. \\
EHESS & École des hautes études en sciences sociales. \\
FAH & Fédération archéologique de l'Hérault. \\
GARA & Groupe alésien de recherches archéologiques. \\
PSO & Préhistoire du Sud-Ouest. \\
PUP & Presses universitaires de Perpignan. \\
RPCPMO & Recherches sur les premières communautés paysannes en Méditerranée occidentale. \\
SPF & Société préhistorique française. \\
SRA & Service régional de l'archéologie.
\end{tabular}

ARNAL J.

1959: "Le mythe de Collorgues (Gard)", $B S P F$, LVI, 6, p. 705-707.

\section{BAILLS H.}

1972: «La cova de la Tortuga», Massana, 16, 4, p. 496-510.

\section{BAZILE F.}

1998: «Matières premières minérales et Paléolithique supérieur en Languedoc oriental: une entreprise délicate", in MisKovsKY J.-C. ET LORENZ J. (DIR.), Pierre et archéologie, Actes du colloque international de Tautavel, 14-16 mai 1998 , Perpignan, éd. PUP (coll. Études), p. 151176.

2002: «Le premier Aurignacien en France méditerranéenne: un bilan», Espacio, tiempo y forma, serie I, Prehistoria y arqueologia, 15, p. 215-236.

\section{BAZILE F., BRESSY C., BRIOIS F.}

2004: «Prospection des affleurements de silex du bassin de Collorgues-Aubussargues", in PLISSON H. (COORD.), Production laminaires remarquables du midi de la France (fin du Néolithique, début de l'âge des Métaux), SRA PACA et Languedoc-Roussillon, inédit, p. 26-34

\section{BERGER G.-M}

1972: Carte géologique de la France (1/500 000), feuille d'Anduze (938), Paris, éd. BRGM, 22 p., 1 carte.

\section{BERTRAND A.}

1866: "Objets offerts à la société», Bulletin de la Société d'Anthropologie de Paris, 1, $2^{\mathrm{e}}$ série, p. 201-204 et p. 236-238.

BINDER D. (DIR.)

1991: Une économie de chasse au Néolithique ancien: la grotte Lombard à Saint-Vallier-deThiey (Alpes-Maritimes), Monographie du CRA n ${ }^{\circ}$ 5, Paris, éd. du CNRS, 243 p.

\section{BOSTYN F., LANCHON Y.}

1992: Jablines, Le Haut Château (Seine-etMarne): une minière de silex au Néolithique, Paris, éd. MSH (coll. DAF, 35), 246 p.

\section{BOCCACCIO G.}

2005: Les Industries lithiques du Solutréen supérieur et du Salpêtrien ancien en Languedoc: ruptures et continuités des traditions techniques, Thèse de $3^{\mathrm{e}}$ cycle, Univ. de Provence, Aix-Marseille-I, 528 p.

\section{BORDREUIL M.}

1975: «Mineurs chalcolithiques en Languedoc oriental », in Actes du $98^{e}$ congrès national des Sociétés savantes, Archéologie, Saint-Étienne, 1973, Paris, Bibliothèque nationale de France, p. 21-28.

1982: "La station Jaussaud à Saint-Mauricede-Cazevieille (Gard)", in Le Néolithique ancien méditerranéen, Actes du colloque international de Préhistoire, Montpellier, 1981, Montpellier, éd. FAH (coll. Archéologie en Languedoc $n^{\circ}$ spécial), p. 265-266.
1984: «Recherches sur la Préhistoire des hautes vallées des Gardons: le Gardon de Saint-Jean et le Bassin de la Droude", in Actes du $106^{e}$ congrès national des Sociétés savantes, Archéologie, Perpignan, 1981 Paris, éd. du CTHS, p. 217-225.

1992: «Recherches sur les rites funéraires dans les cavités de la vallée de la Cèze (nord du département du Gard) », Arenera, 7, p. 37-41.

1996: “Contribution à l'étude de la religion au début des âges des Métaux", in MOHEN J.-P. (DIR.), La Vie préhistorique, Suppl. des Actes du XXIII congrès préhistorique de France, Paris, 3-6 nov. 1989, Dijon, éd. Faton, p. 452-455.

BRESSY C.

2006: "Caractérisation géochimique des silex tertiaires: contribution à l'identification des matières premières diffusées au Néolithique final», in VAQUER J., BRIOIS F. (DIR.), La Fin de l'âge de Pierre en Europe du Sud, Actes de la table ronde de l'EHESS, Carcassonne, 5-6 sept. 2003, Toulouse, éd. AEP, p. 221-231.

\section{BRIOIS F.}

1990: «L'exploitation du silex en plaquettes à Salinelles (Gard): données nouvelles sur les lieux et modes d'extraction, sur les ateliers, problèmes de diffusion ", in Guilaine J., GUTHERZ X. (DIR.), Autour de Jean Arnal, Montpellier, éd. RPCPMO, p. 219-232. 
2005: Les Industries de pierre taillée néolithiques en Languedoc occidental, Lattes, éd. ADAL (coll. Monographies d'archéologie méditerranéenne, 20), $341 \mathrm{p}$.

2006: «Un atelier de production laminaire chalcolithique dans la région des minières de silex de Collorgues (Gard)", in VAQUER J., BRIOIS F. (DIR.), La Fin de l'âge de Pierre en Europe du Sud, Actes de la table ronde de l'EHESS, Carcassonne, 5-6 sept. 2003, Toulouse, éd. AEP, p. 165-174.

CAUliez J.

2007: «Les corpus céramiques du $\mathrm{III}^{\mathrm{e}}$ millénaire av. J.-C. dans le sud-est de la France: identité du groupe Rhône-Ouvèze", $B S P F, 104,1$, p. 125-146.

\section{Cert C.}

2005: «Les outils de métallurgiste du site du Néolithique final de la Capitelle du Broum (Péret, Hérault) ", in AMBERT P., VAQUER J. (DIR.), La Première métallurgie en France et dans les pays limitrophes, Actes du colloque international, Carcassonne, 28-30 sept. 2002, Paris, éd. SPF (coll. Mémoire de la SPF, XXXVII), p. 109-115.

Glop X., Gibaja F.-G., Palomo A., TERRADAS X.

2006: «Approvisionnement, production et utilisation des grandes lames en silex dans le nord-est de la péninsule Ibérique ", in VAQUER J., BRIOIS F. (DIR.), La Fin de l'âge de Pierre en Europe du Sud, Actes de la table ronde de l'EHESS, Carcassonne, 5-6 sept. 2003, Toulouse, éd. AEP, p. 233-246.

\section{COLOMER A.}

1979: Les Grottes sépulcrales artificielles en Languedoc oriental, Toulouse, éd. AEP (coll. AEP, 4), $117 \mathrm{p}$.

\section{COMBIER J.}

1980: "Circonscription Rhône-Alpes ", Gallia Préhistoire, 23, 2, p. 473-524.

\section{Coste A., Gutherz X., RoudiL J.-L.}

1974: «La grotte sépulcrale du Chemin de Fer, à Boucoiran (Gard)", Cahiers ligures de Préhistoire et d'Archéologie, 22-23, p. 73-136.

\section{Courtin J.}

1974: Le Néolithique de la Provence, Paris, éd. Klinksieck (coll. Mémoires de la SPF, 11), $360 \mathrm{p}$.

DAMIANI L.

1967: Carte géologique de la France (1/500 000), feuille d'Uzès (939), Paris, éd. BRGM, 16 p., 1 carte.

\section{DUMAS E.}

1876: Statistique géologique, minéralogique, métallurgique et paléontologique du département du Gard, Paris, éd. Arthus Bertrand, 3 vol., 284 p., 735 p. et 518 p.

\section{DUMAS U.}

1903: «Le préhistorique dans le Gard», Bulletin de la Société d'études des sciences naturelles de Nîmes, XXXI, p. 23-26.

\section{FAGES G.}

1983: «Le tumulus chalcolithique de Dignas, commune de Sainte-Enimie (Lozère)», Actes du congrès préhistorique de France, $X X I^{e}$ session, Montauban-Cahors-Figeac, sept. 1979, Paris, éd. SPF, vol. 2, p. 117-124.

\section{Foucault A., RAOUlt J.-F.}

2000 (5 éd.) : Dictionnaire de géologie, Masson Sciences, Paris, éd. Dunod, 379 p.

\section{FORESTIER A. (DIR.)}

1990: La Grotte de Théris et les gorges de la Cèze, de Tharaux à Montclus, Gard au Chalcolithique, $\mathbb{1}^{e r}$ bilan, CFRAN, inédit, $202 \mathrm{p}$

\section{FURESTIER R.}

2007: Les Industries lithiques campaniformes du sud-est de la France, Oxford, éd. Archeopress (coll. BAR, International Series, 1684), $339 \mathrm{p}$

\section{GISCLON J.-L.}

1982: L'Habitat néolithique et chalcolithique en Languedoc méditerranéen: inventaire des sites de plein air dans une partie du Languedoc oriental, Mémoire de maîtrise de l'Univ. Paul-Valéry, Montpellier-III, 341 p.

\section{GODELIER M.}

1969: "La "monnaie de sel" des Baruya de Nouvelle-Guinée", L'Homme, 9, 2, p. 5-37.

2007: Au fondement des sociétés humaines, ce que nous apprend l'anthropologie, Paris, éd. Albin Michel (coll. Bibliothèque Idées), $294 \mathrm{p}$.

GROS A.-C.

1972: «Compte rendu sommairesurlesfouilles préhistoriques du Serre-de-Boidon à Grospierres (Ardèche) : campagne 1971 ", Les Cahiers du Grospierrois, 5, p. 20-26.

\section{GUTHERZ X., JALLOT L.}

1987: «Statue-menhir et habitat néolithique final de Montaion (Sanilhac-et-Sagriès, Gard), in Actes des journées d'études des statues-menhirs, Saint-Pons-de-Thomières, 5-6 mai 1984, Lattes, éd. FAH, p. 15-36.
HERVÉ M.-L. (DIR.)

1999: ZAC Esplanade Sud, Illot 6 - I, II et III, Nîmes (Gard): diagnostics et fouilles en milieu rural, occupation préhistorique et antique, Nîmes, SRA Languedoc-Roussillon (DFS), 1 vol.

\section{Hugues C.}

1933: «Contributionàl'étude du Paléolithique moyen dans le Gard», Rhodania, 15, Compte rendus du XV congrès, Genève, 1933, Vienne, éd. Martin et Ternet, p. 80-117.

1957: «Sur l'hypogée de Cantagal à Aubussargues", BSPF, LIV, 9, p. 466-469 et p. 661.

Hugues C., DRouot E., GARIMOND S.

1965a: «La station des hypogées de Collorgues (Gard) ", in Congrès préhistorique de France, Compte rendus de la XVI e session, Monaco, 28 août-16 sept. 1959, Paris, éd. SPF, p. 656-673.

1965b: «Les hypogées de Collorgues (Gard) », $B S P F$, LXII, 1, p. 209-220.

HUgues C., GUTHERZ X., BORdReUIL M.

1974: «La station de Figaret, Collorgues (Gard)", Cahiers ligures de Préhistoire et d'Archéologie, 22-23, p. 31-72.

IhUel E., Mallet N., Louboutin C.

2002: "Les collections pressigniennes du musée des Antiquités nationales de SaintGermain-en-Laye», Antiquités nationales, 34, p. 29-76.

JALLOT L. (DIR.)

2004: Le Mas de Vignoles IV, à Nîmes (Gard), Nîmes, SRA Languedoc-Roussillon (DFS), 11 vol.

\section{JEANJEAN A.}

1885: L'Âge du Cuivre dans les Cévennes, extrait des Mémoires de l'Académie de Nîmes, $\mathrm{VII}^{\mathrm{e}}$ série, t. 7, année 1884, Nîmes, éd. Clavel et Chastanier, $16 \mathrm{p}$.

LÉA V.

2004: Les Industries lithiques du Chasséen en Languedoc oriental: caractérisation par l'analyse technologique, Oxford, Archeopress (coll. BAR, International Series, 1232), $215 \mathrm{p}$

\section{LOMBARD-DUMAS A.}

1879: «Mémoire sur la céramique antique dans la vallée du Rhône d'après les notes et la collection d'Émilien Dumas, de Sommières", extrait des Mémoires de l'Académie de Nîmes, VII ${ }^{\mathrm{e}}$ série, t. 1, année 1878, Nîmes, éd. Clavel et Chastanier, 94 p. 


\section{LOMBARD-DUMAS A., ROUSSET L.}

1887: «Note sur une sépulture mégalithique découverte dans la commune de Collorgues (Gard) », extrait des Mémoires de l'Académie de Nîmes, VII série, t. 9, année 1886, Nîmes, éd. Clavel et Chastanier, p. 203-215.

\section{MALLET N.}

1992: Le Grand Pressigny: ses relations avec la civilisation Saône-Rhône, Tours, éd. du CTHS (coll. Suppl. au Bulletin des amis du musée de Préhistoire du Grand-Pressigny), 2 vol., 228 p.

\section{MANOLAKAKIS L.}

2006: «Les très grandes lames de Varna (Bulgarie): quelle fonction?", in VAQUER J., BRIOIS F. (DIR.), La Fin de l'âge de Pierre en Europe du Sud, Actes de la table ronde de l'EHESS, Carcassonne, 5-6 sept. 2003, Toulouse, éd. AEP, p. 5-23.

\section{MORTILLET P. (DE)}

1914: Origine du culte des morts: les sépultures préhistoriques, Paris, éd. Gambier (coll. Bibliothèque préhistorique), 123 p.

\section{NicOlas H.}

1889: «Sépultures de Collorgues », Association française pour l'avancement des sciences, Congrès de Paris, $18^{e}$ session, $2^{\mathrm{e}}$ partie, p. $626-637$.

\section{PANOFF M.}

1980: "Objets précieux et moyens de paiement chez les Maenge de NouvelleBretagne", L'Homme, 20, 2, p. 5-37.

\section{PELEGRIN J.}

2002: «La production des grandes lames de silex du Grand-Pressigny", in GUILAINE J. (DIR.), Matériaux, productions, circulations du Néolithique à l'âge $d u$ Bronze, Paris, éd. Errance, p. 131-148.

2005: "L'extraction du silex au GrandPressigny pendant le Néolithique final: proposition d'un modèle", Bulletin des amis du musée de Préhistoire du GrandPressigny, 56, p. 67-71.

PERRIN T., BRIOIS F.

2005: "L'industrie lithique taillée», in CArroza L. (DIR.), La Fin du Néolithique et les débuts de la métallurgie en Languedoc central: les habitats de la colline du PuechHaut à Paulhan, Hérault, Toulouse, éd. AEP, p. 405-417.

Peyrolles D. et R.

1959: «Les galeries de mines et la Vigne du Cade », BSPF, LVI, 9-10, p. 525-531.

\section{POLANYI K.}

1968: Primitive, Archaic and Modern Economies: Essays of Karl Polanyi edited by George Dalton, Garden City, New York, Anchor Books, $346 \mathrm{p}$.

\section{RAYMOND P.}

1900: L'Arrondissement d'Uzès avant l'histoire, Paris, éd. F. Alcan, $263 \mathrm{p}$.

1905: «Les maillets de Malaucène (Vaucluse) : puits d'extractions et tailleries de silex néolithiques", $B S P F$, II, 1, p. 17-26.

1907: "Note sur les lames de Collorgues (Gard) ", Revue préhistorique, II, p. 255.

\section{REMICOURT M.}

2006: «Premier aperçu des industries lithiques taillées présentes dans les niveaux du Néolithique final du Mas de Vignoles IV, à Nîmes (Gard)", in BREUIL J-Y. (COORD.), PCR: Espace rural et occupation du sol de la région nîmoise de la Préhistoire récente à l'époque moderne, Nîmes, SRA Languedoc-Roussillon, p. 85-119.

2007: «Contribution à l'inventaire des productions laminaires du Languedoc oriental: les grandes lames conservées au musée du Colombier (Gard)", in PLISSON H. (COORD.), Rapport d'activité: productions laminaires remarquables du Midi de la France (fin du Néolithique, début de l'âge des Métaux), inédit.

\section{REMICOURT M., BRESSY C.}

2007: «Les grandes lames à la fin du Néolithique à Nîmes", in BREUIL J-Y. (COORD.), PCR: Espace rural et occupation du sol de la région nîmoise de la Préhistoire récente à l'époque moderne, Nîmes, SRA Languedoc-Roussillon, p. 46-58.

\section{RENAULT S.}

1998: «Économie de la matière première: l'exemple de la production au Néolithique final en Provence, des grandes lames en silex zoné oligocène du bassin de Forcalquier (Alpes-de-HauteProvence)", in D'ANNA A., BINDER D. (DIR.), Production et identité culturelle, Actes des $2^{e}$ rencontres méridionales de Préhistoire récente, Arles, 8-9 nov. 1996, Antibes, éd. APDCA, p. 145-161.

2006: «La production des grandes lames au Néolithique final en Provence: matériaux exploités, multiplicité des productions, aspects technologiques et culturels", in VAQUER J., BRIOIS F. (DIR.), La Fin de l'âge de Pierre en Europe du Sud, Actes de la table ronde de l'EHESS, Carcassonne, 5-6 sept. 2003, Toulouse, éd. AEP, p. 139-164.

\section{RENFREW C.}

1984: Approaches to Social Archaeology, Edinburg, éd. Edinburg University Press, $430 \mathrm{p}$.

\section{ROUVERAND E.-J.}

1897: Saint-Hilaire-de-Brethmas, monographie communale, Nîmes, éd. Laporte, 32 p.

ROUDIL J.-L.

1984: «L'occupation néolithique de la baume d'Oulen», Ardèche Archéologie, 1, p. 14-18.

\section{Roudil J.-L., SAUMAdE H.}

1985: «Stratigraphies comparées du Néolithique ardéchois", Ardèche Archéologie, 2, p. 12-22

\section{SAlles J., BordReuil M.}

1965: "Alès et sa région avant les temps historiques", Causses et Cévennes, $\mathrm{X}, \mathrm{n}^{\circ} 2$, p. $287-294$

SAlles J., Brousse M., Louis M.

1950: «La grotte de la Rouquette (commune de Saint-Hilaire-de-Brethmas, Gard) », Rivista di Studi Liguri, XVI, 1-3, p. 107117.

\section{SAlles J., Magne P., Bordreuil M.}

1977: «Une exploitation minière remployée comme nécropole: la grotte de la Rouquette (Saint-Hilaire-de-Brethmas, Gard) ", in Mines et mineurs en LanguedocRoussillon et régions voisines de l'Antiquité à nos jours, Actes du XLIX $X^{e}$ congrès de la Fédération historique du Languedoc méditerranéen et du Roussillon, Alès, 22-23 mai 1976, Montpellier, La Fédération (coll. Congrès de la Fédération historique du Languedoc méditerranéen et du Roussillon, 49), p. 13-22.

\section{SAUZADE G.}

1975: «Le dolmen de Peicervier à Lorgues (Var) et les poignards à soie courte en silex poli du midi de la France", Bulletin du Muséum d'histoire naturelle de Marseille, XXXV, p. 241-258

\section{SCIMIA R., VARÉA S.}

1996: La Grotte de la Rouquette, Saint-Hilairede-Brethmas (30), au Néolithique final, Alès, éd. GARA, $154 \mathrm{p}$.

\section{SERVET J.-M.}

1993: "L'institution monétaire de la société selon Karl Polanyi », Revue économique, 44, 6, p. 1127-1150.

\section{Soutou A}

1967: «Les grottes sépulcrales de La Médecine 
et de La Graillerie à Verrières (Aveyron) : deux milieux clos de l'Énéolithique des Grands Causses», Gallia Préhistoire, X, 2, p. $237-272$.

\section{TAMAIN G.}

1959: «Considérations géologiques et lithologiques sur les puits de mines de la Vigne du Cade (La Rouvière), Salinelles (Gard) », BSPF, LVI, 9-10, p. 533-537.

\section{VAQUER J.}

1990: Le Néolithique en Languedoc occidental, Paris, éd. du CNRS, 398 p.

1999: «Les origines préhistoriques de Carcassonne ", Bulletin de la Société d'études scientifiques de l'Aude, XCIX, p. 17-36.

VaQuer J., Gandelin M., Briois F., MONTÉCINOS A., AMBERT P.

2006a: «Les industries en silex allochtones de la grotte Tournié (Pardailhan, Hérault) : contribution à la chronologie des importations de productions lithiques remar- quables en Languedoc occidental", in VAQUER J., BRIOIS F. (DIR.), La Fin de l'âge de Pierre en Europe du Sud, Actes de la table ronde de l'EHESS, Carcassonne, 5-6 sept. 2003, Toulouse, éd. AEP, p. 205-220.

VAQUer J., Remicourt M. avec la coll. de BORDREUIL M.

(À paraître) : «Les longues lames en silex au Chalcolithique dans le midi de la France entre Rhône et les Pyrénées", in Actes de la table ronde internationale de Tours, 7-8 sept. 2007, Des grandes lames en silex dans toute l'Europe à la fin du Néolithique: production, diffusion, signification.

\section{VAQUER J., REMICOURT M., VERGÉLY H.}

2006b: «Les poignards métalliques et lithiques du Chalcolithique pré-Campaniforme des petits et Grands Causses dans le midi de la France», in GASCO J., LEYGE F., GRUAT P. (DIR.), Hommes et passés des Causses: hommage à Georges Costantini,
Actes du colloque de Millau, 16-18 juin 2005, Toulouse, éd. AEP, p. 155-179.

\section{VAQUER J., VERGÉLY H.}

2006: «L'utilisation du silex en plaquette dans le Néolithique final et le Chalcolithique du sud du Massif central aux Pyrénées", in VAQUER J., BRIOIS F. (DIR.), La Fin de l'âge de Pierre en Europe du Sud, Actes de la table ronde de l'EHESS, Carcassonne, 5-6 sept. 2003, Toulouse, éd. AEP, p. 175-204.

VAQUer J., Vergély H., GANDELIN M., BRESSY C., BELlot-GuRlet L., PLISSON H.

2006c: «Place et rôle des composantes allochtones dans les industries lithiques taillées du site de Mourral (Trèbes, Aude)", in Fouéré P., CheVillot C., COURTAUd P., Ferullo O., Leroyer C. (DIR.), Paysages et peuplements: aspects culturels et chronologiques en France méridionale, Périgueux, éd. PSO, p. 347-363. 